\title{
EVALUATION OF STIRRUP RUPTURES THROUGH EXPERIMENTAL AND ANALYTICAL SIMULATIONS OF ASR EXPANSION
}

\author{
Yulong ZHENG ${ }^{1}$, Kenji KOSA ${ }^{2}$ and Nobuo UEHARA ${ }^{3}$ \\ ${ }^{1}$ Student Member of JSCE, Dept. of Civil Eng., Kyushu Institute of Technology \\ (1-1, Sensui-cho, Tobata-ku, Kitakyushu-shi, Fukuoka 804-8550, Japan) \\ E-mail: zylpuff@gmail.com \\ ${ }^{2}$ Member of JSCE, Professor, Dept. of Civil Eng., Kyushu Institute of Technology \\ (1-1, Sensui-cho, Tobata-ku, Kitakyushu-shi, Fukuoka 804-8550, Japan) \\ E-mail: kosa@civil.kyutech.ac.jp \\ ${ }^{3}$ Member of JSCE, Cement / Concrete Research Laboratory, Sumitomo Osaka Cement Co., Ltd., \\ (6-28, Rokubancho, Chiyoda-ku, Tokyo 102-8465, Japan) \\ E-mail: nuehara@soc.co.jp
}

\begin{abstract}
To estimate the behavior of stirrups, which is necessary for understanding the reason for stirrups rupturing due to Alkali-Silica Reaction (ASR), experiments simulating ASR expansion were conducted. Using $1 / 4$ scale of the actual structure with ruptured stirrups, specimens were made by casting expansive mortar into the square hollow of ordinary concrete set to provide adhesion for the stirrup. FEM analysis was also performed to further evaluate the movement behavior. The results showed that corresponding to external cracking caused by bending and tensile effects, ASR-induced uniform elongation and circular-arc deformation were generated. Further, owing to the influence of circular-arc deformation, angular opening of the corner stirrup with angular increment was verified directly for the bent section of the stirrup. This was confirmed to induce the progress of crack initiations in stirrups and even ruptures.
\end{abstract}

Key Words: ASR, experiment, FEM analysis, circular-arc deformation, stirrup rupture

\section{INTRODUCTION}

In recent years, due to Alkali-Silica Reaction (ASR), many concrete structures have been affected by significant deterioration. For example, numerous bridges in Japan have ruptures in the bent section of stirrups due to $\mathrm{ASR}^{1)}$. Therefore, efforts have been made to identify the rupture mechanism. Based on a JSCE report ${ }^{2}$, one of the mainstream estimations is shown in Fig. 1. First, during the bending process, local strain concentration is produced near the root of ribs, which induces the generation of crack initiation (A of Fig. 1). Second, considering there is very little plastic deformation and a radial pattern from the crack initiation in the rupture surface ${ }^{3)}$, angular opening of the corner stirrup was presumed to generate, which led to the progress of crack initiation $(B)$.

Therefore, experiments were conducted for further validation. For instance, according to Sasaki et al. ${ }^{4}$, the bending process for the current marketing rebar was performed at different bending radii. When at the smaller bending radius of 1.0 rebar diameter, crack

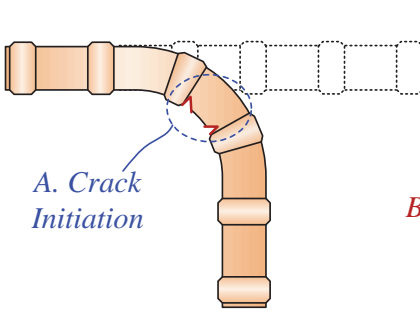

(a) Bending Process

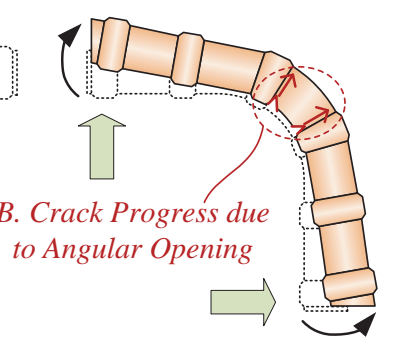

(b) After Expansion
Fig. 1 Estimated mechanism.

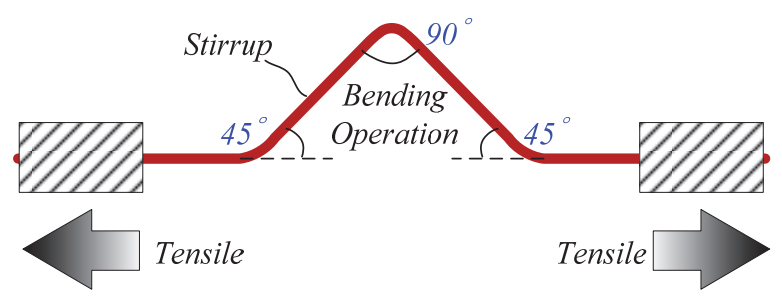

Note: From tensile test of stirrups after bending operation ${ }^{5)}$.

Fig. 2 Tensile test in previous research. 
initiation appeared in the bent section of the stirrup by crushing of ribs due to the effect of the bar bender. Further, specimens using expansive mortar, which were equivalent to $1 / 8$ of the actual bride pier beam, were manufactured based on Kosa et al. ${ }^{5}$. Greater progress of crack initiation occurred for stirrups with steep rib shapes. Ninety percent of propagations generated right in the middle of inner bent section. Whereas, the actual reinforcement condition did not reappear as only few stirrups were applied. Rupture failed to occur since the current marketing rebar was mainly adopted. The reason for propagation of crack initiation together with stirrup motion has not been discussed.

Additionally, as shown in Fig. 2, Shinno et al. ${ }^{6)}$ performed a tensile test acting on two ends of the stirrup which had a bending process of 1.0 diameter, to simulate the angular opening of the corner stirrup. As to the stirrup which had the greatest crack initiations during the bending process, a brittle rupture surface similar to the actual ASR-influential structures occurred in four of the six stirrups before reaching the yield or the tensile strengths. Thus, the angular opening of the corner stirrup is significant for reproducing the brittle rupture surface. Nevertheless, the deformation of the corner stirrup here was not real but simulated by the tensile test. Kusano et al. ${ }^{7), 8}$ performed experiments applying expansive mortar and reactive aggregates for expansion. As a result, circular-arc deformation was confirmed on concrete surface, which was considered to be responsible for generating the angular opening of corner stirrup.

The main insufficiencies of the researches described above are summarized in Fig. 3. Deformation and cracking by the ASR-induced expansion were evaluated. However, the mechanisms for generation were not clear. In addition, along with the external deformation behavior, the actual stirrup motion was not elucidated. Therefore, the following topics were investigated in the current study:

Topic 1: Stirrup performance was examined to identify the real stirrup motion and its influence on the progress of crack initiation.

Topic 2: The generation mechanism of concrete deformation and cracking was evaluated to understand the casual factors of the deformation condition of the stirrup.

Applying four specimens using expansive agent and size as $150 \mathrm{~mm} \times 150 \mathrm{~mm} \times 490 \mathrm{~mm}$ under the uniaxial restraint situation ${ }^{9)}$, the expansive amount was found to obviously decrease as the level of restraint was increased. This is similar to the results obtained by the actual ASR specimens ${ }^{10}$. Consequently, referring to Fig. 4, expansive mortar was applied in an ASR-simulation specimen to understand the time history of stirrup motion and the features of concrete

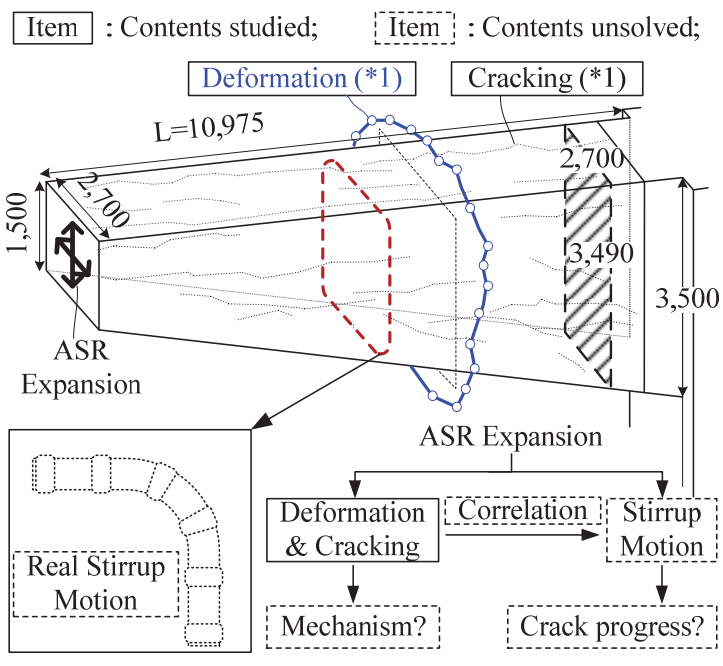

*1: Cracking \& deformations are based on image.

Fig. 3 Summary of insufficiencies.

\begin{tabular}{|c|c|}
\hline \multicolumn{2}{|c|}{ BACKGROUND } \\
\hline \multicolumn{2}{|c|}{$\begin{array}{l}\text { Stirrup motion by ASR has not been validated distinctly; } \\
\text {-Generation mechanism of concrete damage is not clear. }\end{array}$} \\
\hline \multicolumn{2}{|c|}{ \} } \\
\hline \multicolumn{2}{|c|}{ STUDY OBJECTIVE } \\
\hline \multicolumn{2}{|c|}{$\begin{array}{l}\text { - Find real stirrup motion as well as its influence on progress } \\
\text { of initiating crack in stirrup; } \\
\text { - Figure out generation mechanism of concrete damage to } \\
\text { understand casual factors for deformation of stirrup. }\end{array}$} \\
\hline \multicolumn{2}{|c|}{ S } \\
\hline \multicolumn{2}{|c|}{ STUDY CONTENT } \\
\hline ASR-Simulation Tests & FEM Analysis \\
\hline $\begin{array}{l}\text { Features of cracking \& } \\
\text { deformation; } \\
\text { Stirrup motion \& crack. }\end{array}$ & $\begin{array}{l}\text { - Generation mechanism } \\
\text { of concrete damage; } \\
\text { - Rupture reason. }\end{array}$ \\
\hline Con & \\
\hline
\end{tabular}

Fig. 4 Study flow.

damage. Further, in combination with the experimental results, FEM analysis was conducted to understand the mechanism of concrete damage and the influence of stirrup motion on the progress of crack initiation.

\section{EXPERIMENTAL CONDITIONS}

In this chapter, the experimental conditions are introduced for a better understanding of the general considerations and basic conditions of the simulation tests.

\section{(1) Considerations for modeling}

The object for modeling the current specimens is a PC bridge pier beam (refer to the size condition in Fig. 3), which has served for over 30 years. The ASR- 
induced deteriorations and multiple ruptures of a stirrup in the bent part were confirmed. As critical failure might occur, a cross-section of $3490 \mathrm{~mm} \times 2700 \mathrm{~mm}$ near the root of the beam was adopted for modeling. To simulate uniform expansion from ASR, a square cross-section of $680 \mathrm{~mm} \times 680 \mathrm{~mm}$ nearly $1 / 4$ scale was applied to specimens.

This study examined the effect of ASR-induced inner expansion on damage to external concrete and stirrup fractures. In general, it takes several years for damage by ASR to become evident. To simulate the ASR-induced expansion in the short term, expansive mortar was used. In actual ASR expansion, many factors like creep, dry shrinkage, and anisotropic behavior etc. are very influential ${ }^{11),}{ }^{12)}$. In this study, applying the expansive mortar, the main purpose was set to simply simulate the ASR expansive force itself, which was imaged to be the totally ultimate force after suffering the integrated influence from the timedependent factors described above. Based on previous studies ${ }^{13), 14)}$, the inner expansive force was considered to be critical on the exterior damage. Thus, a frame of ordinary concrete with 28 days' curing age was arranged in the current specimens, to simply learn about the influence of internal expansive force on the movement and ruptures of corner stirrup.

\section{(2) Specimen conditions}

Using parameters such as different stirrup ratio, rebar type or expansion amount (details can be referred in previous study ${ }^{7}$ ), specimens (Case 11 to 16) of $1 / 4$ of the actual pier beam were made. Brittle rupture surfaces were generated ${ }^{7}$, which were similar to ASR-influenced structures. In this study, considering the successful reproduction of actual stirrup ruptures, Case 14 and Case 16 with a larger casting area of expansive mortar and different size of frame concrete were used as representative.

As to Case 14 (Fig. 5(a) and 5(c)), the external size was $680 \mathrm{~mm} \times 680 \mathrm{~mm} \times 1340 \mathrm{~mm}$ with a cross-section of $1 / 4$ to the actual pier beam. Further, the dimension of the expansive mortar was set as $456 \mathrm{~mm} \times 456$ $\mathrm{mm}$. Herein, the thickness of frame concrete was 112 mm greater than $95 \mathrm{~mm}$, which was needed to provide sufficient adhesion for stirrups ${ }^{5}$. The thickness was also decided by placing the stirrup and the main rebar in the middle of ordinary concrete and using the covering layer as close to the minimum status $40 \mathrm{~mm}$ of actual structure. The spacing of stirrups was 285 mm with a stirrup ratio of $0.22 \%$, which was the same as the pier beam.

Specimen conditions for Case 16 are illustrated in Fig. 5(b) and 5(d). In order to study the influence of different restraints of frame concrete, the dimensions of the cross-section for expansive mortar was the same as $456 \mathrm{~mm} \times 456 \mathrm{~mm}$; while the size of frame

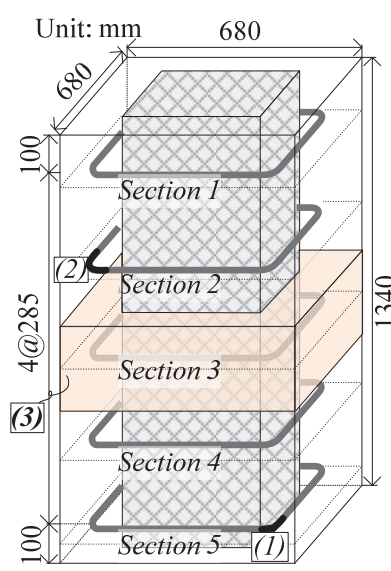

(a) Specimen (Case 14)

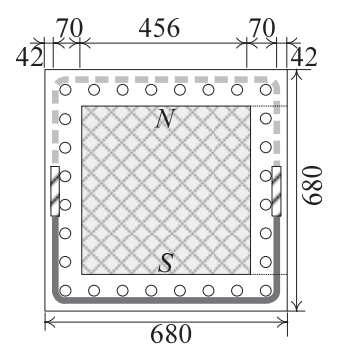

(c) Sectional View (Case 14)

\begin{tabular}{|c|c|}
\hline$-=-n$ & Current type \\
\hline$\square$ & Old type B \\
\hline & Old type C \\
\hline
\end{tabular}

(e) Rebar Types

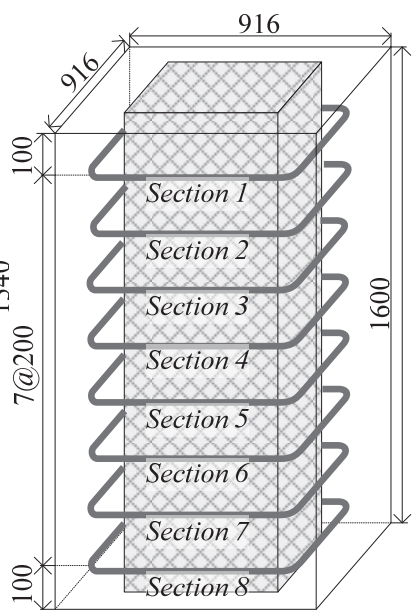

(b) Specimen (Case 16)

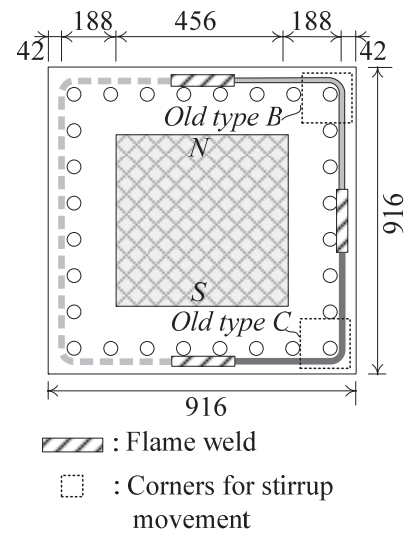

(d) Sectional View (Case 16)
Fig. 5 Specimen conditions.

Table 1 Mix proportion of frame concrete.

\begin{tabular}{c|c|c|c|c|c|c|c}
\hline \multirow{2}{*}{$\begin{array}{c}\mathrm{G}_{\max } \\
(\mathrm{mm})\end{array}$} & \multirow{2}{*}{$\begin{array}{c}\mathrm{W} / \mathrm{C} \\
(\%)\end{array}$} & $\mathrm{s} / \mathrm{a}$ & \multicolumn{5}{|c}{ Unit $\left(\mathrm{kg} / \mathrm{m}^{3}\right)$} \\
\cline { 4 - 8 } & $(\%)$ & $\mathrm{W}$ & $\mathrm{C}$ & $\mathrm{S}$ & $\mathrm{G}$ & $\begin{array}{c}\text { Admi- } \\
\text { xture }\end{array}$ \\
\hline 20 & 46 & 43 & 175 & 381 & 718 & 1018 & 1.142 \\
\hline
\end{tabular}

Table 2 Mix proportion of expansive mortar.

\begin{tabular}{c|c|c|c|c|c}
\hline $\mathrm{W} /(\mathrm{C}+\mathrm{E})$ & $\mathrm{E} /(\mathrm{C}+\mathrm{E})$ & \multicolumn{4}{|c}{ Unit $\left(\mathrm{kg} / \mathrm{m}^{3}\right)$} \\
\cline { 3 - 6 }$(\%)$ & $(\%)$ & $\mathrm{W}$ & $\mathrm{C}$ & $\mathrm{S}$ & $\mathrm{E}$ \\
\hline 29.8 & 25.8 & 231 & 575 & 1150 & 200 \\
\hline
\end{tabular}

concrete was $230 \mathrm{~mm}$ greater than the $112 \mathrm{~mm}$ of Case 14. The spacing of stirrups was $200 \mathrm{~mm}$ to make an identical stirrup ratio of $0.22 \%$. As in Fig. 5(c) and 5(d), stirrups adopted the D16 rebar with one type using a rib shape based on current specifications ('current type' for short) and two types using bamboo joints (ribs aligned in parallel with spacing) based on old specifications ('old type' B and C). More details 
on rebar types can be found in previous research ${ }^{7)}$.

\section{(3) Material conditions}

With respect to material properties, the mix proportions for frame concrete and expansive mortar are presented in Tables 1 and 2, respectively. Frame concrete adopts a strength of $27 \mathrm{~N} / \mathrm{mm}^{2}$ as the design strength for the actual pier beam. By cylinder tests after 28 days' curing, the real strength of $35 \mathrm{~N} / \mathrm{mm}^{2}$ was obtained. To simulate inner expansion from ASR quickly, a lime-type expansion agent was applied. The expansion agent was set as $200 \mathrm{~kg} / \mathrm{m}^{3}$ to reproduce severe deterioration conditions. In addition, in order to imitate strain aging in the bent section of a stirrup, all rebars after the bending process were heated under an electric furnace for 10 hours at $120^{\circ} \mathrm{C}$. Consequently, 6 years’ progression of strain aging was resulted ${ }^{15)}$.

\section{(4) Measurement items}

Here, the measurement items are introduced. To understand the damage behavior of frame concrete and inner stirrups induced by the effect of inner expansion, external cracking, deformation, and damage produced in inner stirrups were measured for both cases. To evaluate the movement of stirrups directly, the shapes of stirrups were recorded before and after expansion for Case 16. Detailed measurement methods and results are evaluated in subsequent chapters.

\section{MECHANISM EVALUATION FOR GENERATION OF CRACKING}

Regarding Topic 2 (to learn about the casual factors for deformation conditions of a stirrup, the generation mechanism of cracking and deformation was evaluated), the effects from expansion were studied through evaluation for classified cracking herein.

\section{(1) General cracking conditions}

The measurement method for cracking is illustrated in Fig. 6. Measuring lines with an interval of $100 \mathrm{~mm}$ were drawn in a transverse direction to the main rebar before expansion. Cracking was measured by crack gauge and sketched at $1.0 \mathrm{hr}$ interval when the development was acute; while a longer time interval was applied in a smaller pace. Measurement objectives were cracking with width greater than 0.05 $\mathrm{mm}$. Further, in order to study the characteristics of cracking in different regions, evaluation areas were divided with a corner area for frame concrete and center area for the other region (refer to Fig. 6).

Thus, to study the influence from inner expansion on the damage level of concrete, the cracking density and strain were evaluated (definitions in Fig. 6).

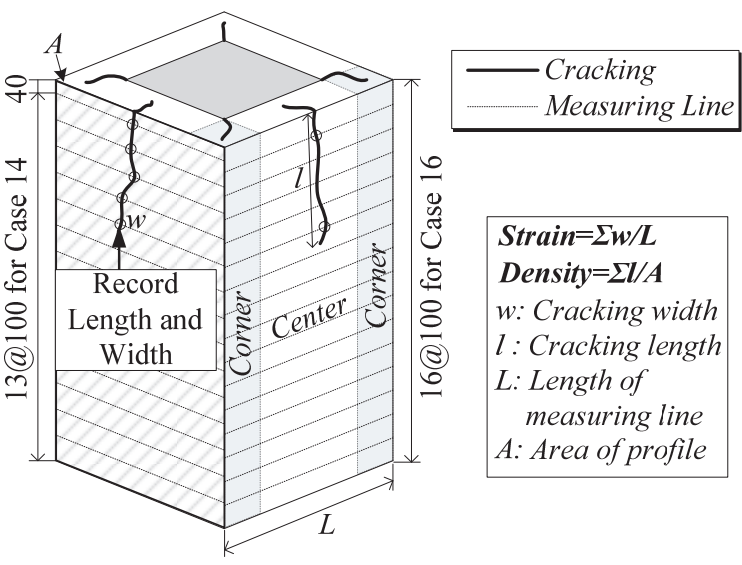

Fig. 6 Measuring method of cracking.

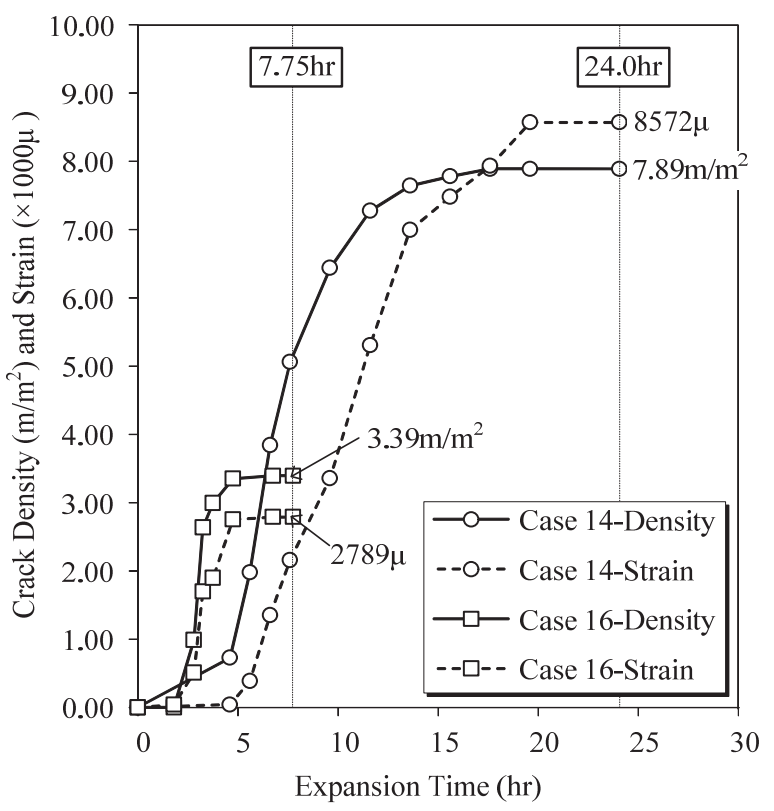

Fig. 7 Comparison of cracking density and strain.

-....... Crack with width $<0.2 \mathrm{~mm}$ - Crack with width $>0.2 \mathrm{~mm}$

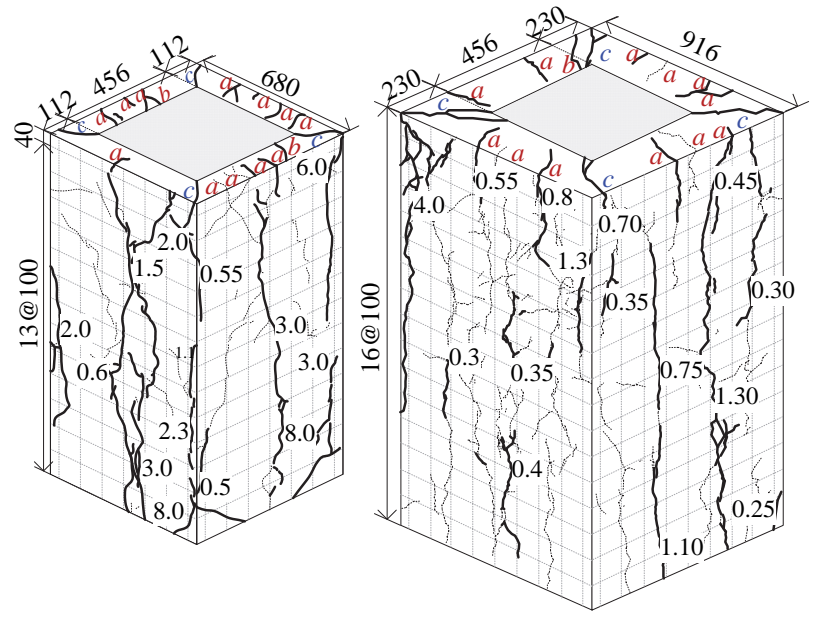
(a) Final (After 24.0hr, Case 14)
(b) Final (After 7.75hr, Case 16)

Fig. 8 General cracking form. 
Herein, as a boundary width to perform reinforcement in structure ${ }^{16)}$, cracking greater than $0.2 \mathrm{~mm}$ was counted for computation of cracking density; cracking strain was defined as the ratio of the sum for cracking width in the measuring line to the length of the measuring line as $680 \mathrm{~mm}$ for Case 14 and 916 $\mathrm{mm}$ for Case 16 (refer to Figs. 5 and 6). Thus, the time evolution of cracking strain and density is shown in Fig. 7. Due to different casting seasons of two cases (Case 14 in winter and Case 16 in summer), the maximum expansion time was $24.0 \mathrm{hr}$ for Case 14, which was greater than $7.75 \mathrm{hr}$ of Case $16(0 \mathrm{hr}$ as the time point when expansive mortar had just been cast). However, both cases had a similar variation trend as an acute increment at first and the tendency to converge.

For cracking density, the maximum was $7.89 \mathrm{~m} / \mathrm{m}^{2}$ for Case 14, which was 2.3 times the $3.39 \mathrm{~m} / \mathrm{m}^{2}$ for Case 16. Whereas, for cracking strain, the maximum $8572 \mu$ for Case 14 was 3.1 times the $2789 \mu$ for Case 16. By increasing the size of frame concrete without expansion, the cracking strain had more influence, which suggests that multiple cracking with a small width might occur for Case 16. Referring to research $^{7)}$, the cracking density and strain of a pier beam with ruptures were $2.9 \mathrm{~m} / \mathrm{m}^{2}$ and $2464 \mu$, respectively. The current two cases show sufficient damage level to induce stirrup rupture. Thus, to check the general cracking form, Fig. 8 presents the final surface cracking for Cases 14 and 16. Longitudinal cracking was generated in both corners and center areas. Regarding the actual ASR-influential pier beam, cracking was also confirmed to occur in both the center and corner of the profile along with the main rebar $^{5)}$. In comparison with Case 14, cracking of Case 16 showed a similar form. While due to the greater restraint from frame concrete, integral cracking widths of Case 16 were on a smaller level, which corresponds to that described in Fig. 7.

As a result, the absolute cracking indicators were different due to the specimen conditions. However, the general cracking form and the time variation trend in cracking densities and strains were similar to those of the actual structures as a whole.

\section{(2) Time development of cracking}

In order to understand the generation features of cracking and to study the physical impacts from expansion, the time variation of cracking was evaluated. Figure 9 shows the record for Case 14 (for the south profile for instance, refer to Fig. 5). Cracking widths were divided with a boundary $0.2 \mathrm{~mm}$. After $8.0 \mathrm{hr}$ of expansion, first cracking occurred in the longitudinal direction of the center area. After $10 \mathrm{hr}$, new cracking appeared in both the corner and the center.
Crack with width $<0.2 \mathrm{~mm}-$ Crack with width $>0.2 \mathrm{~mm}$

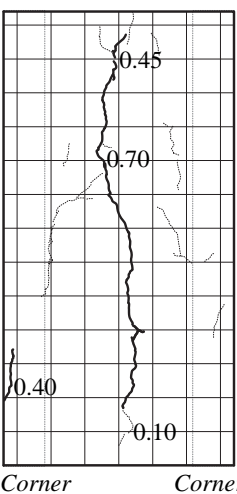

(a) After $8.0 \mathrm{hr}$

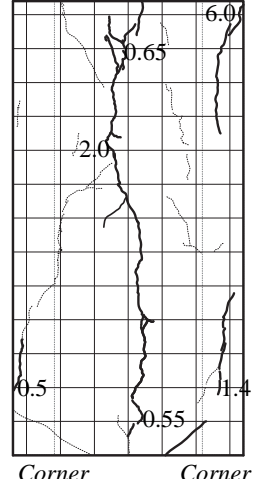

(b) After $10.0 \mathrm{hr}$

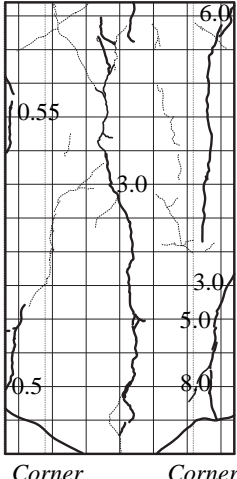

(c) Final (After 24.0hr)
Fig. 9 Time variation of cracking in surfaces (Case 14).

Crack with width $<0.2 \mathrm{~mm}-$ Crack with width $>0.2 \mathrm{~mm}$

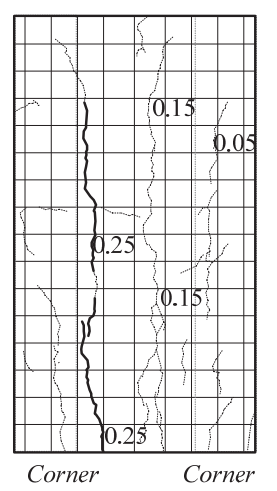

(a) After $2.80 \mathrm{hr}$

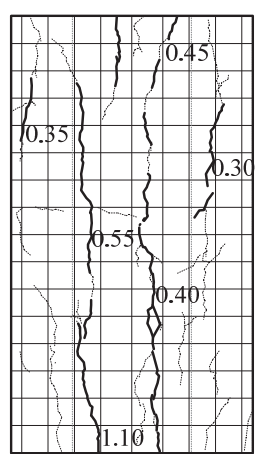

Corner

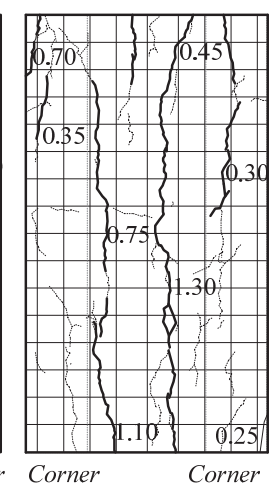

(c) Final (After 7.75hr)
Fig. 10 Time variation of cracking in surfaces (Case 16).

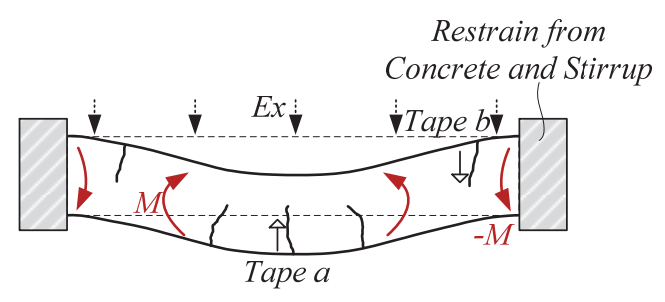

(a) Image for Crack in Center

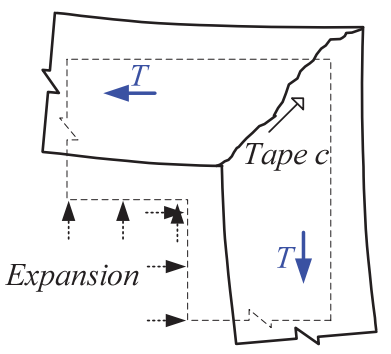

(b) Image for Crack in Corner

Fig. 11 Classification for cracking types. 
Finally, after $24.0 \mathrm{hr}$, new cracking was slightly produced with the width increasing to $3.0 \mathrm{~mm}$ in the center and $8.0 \mathrm{~mm}$ in the corner. For contrast, Fig. 10 shows the evolution of Case 16 (south profile). Similarly, cracking in the greater width occurred in the center first after $2.80 \mathrm{hr}$. Thus, new cracking appeared in both areas after $3.25 \mathrm{hr}$. In the final state, almost no new cracking was generated with the maximum width rising to be $1.30 \mathrm{~mm}$ and $0.70 \mathrm{~mm}$ for the center and the corner, respectively. Similar to findings of previous research ${ }^{5)}$, two cases also had variations in cracking arising in the center and then in the corner, while further growth only occurred in width from existing cracking subsequently.

In general, cracking developed in the longitudinal direction due to the smaller restraint of the lateral stirrups. By increasing the size of the frame concrete, the cracking in the profile of Case 16 had a similar form and time variation trend to that of Case 14 . Whereas, the general cracking widths of Case 16 were on a smaller level. Figure 8 shows that cracking roughly connected between the profile and the upper section. In the evaluation of cracking types in order to understand the generation mechanism, cracking in the upper section was examined subsequently.

\section{(3) Classification and comparison of cracking types}

Cracking types are classified below. Figure 11 presents an image of cracking in the upper section together with the possible generating mechanism. As in Fig. 11(a), due to greater restraint from the concrete and stirrup in the corner area, a positive bending moment will act on the center area of the frame, which induces cracking generation from the exterior (Type a). Simultaneously, due to the rigid constraint in the corner area, negative bending moment will also impact on regions close to corner areas, which causes cracking propagation from the interior (Type $b$ ). An image of cracking in the corner part is shown in Fig. 11(b). Affected by uniform inner expansion, uniform tension ( $T$ ) was also generated, which induced cracking to spread throughout in the diagonal direction (Type $c$ ).

Consequently, cracking types for Case 14 and Case 16 are illustrated in Fig. 12(a) and 12(b), respectively. It was clarified that Type $a$ mainly occupied the center while Type $c$ was the main type in the corner. Further, the numerical statistics for cracking numbers of each type are displayed in Fig. 12(c). Although with slight variations for cracking numbers, with increasing size of frame concrete in Case 16, no great change was found for cracking type.

As a feature of cracking, by increasing the size of frame concrete, cracking strain and density decreased by over one half. However, the amount for each
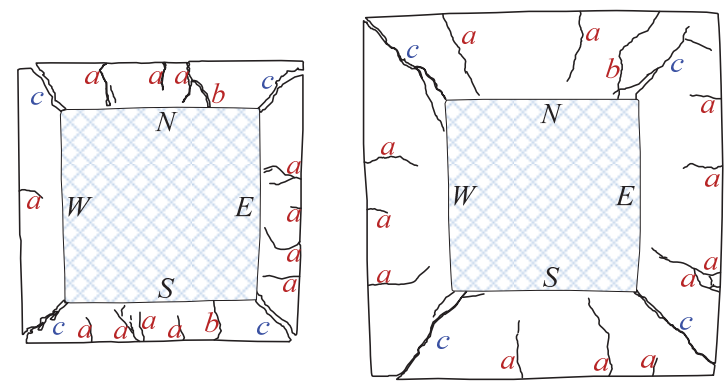

(a) Upper Section (Final, Case 14)

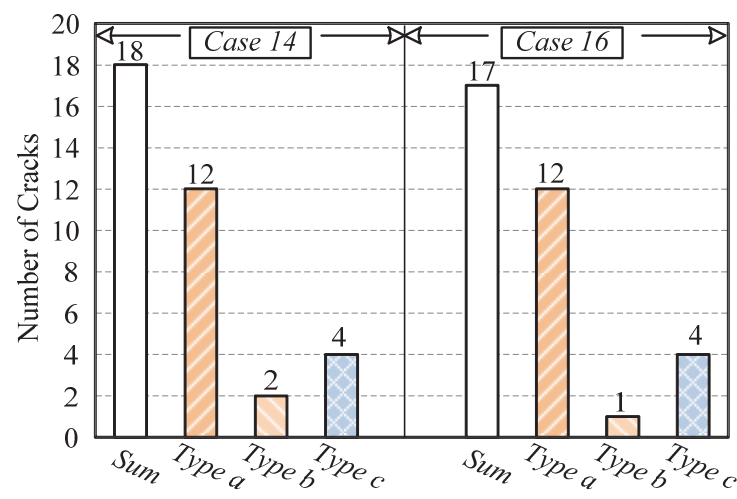

(c) Numeric Comparisons

Fig. 12 Classification of cracking types.

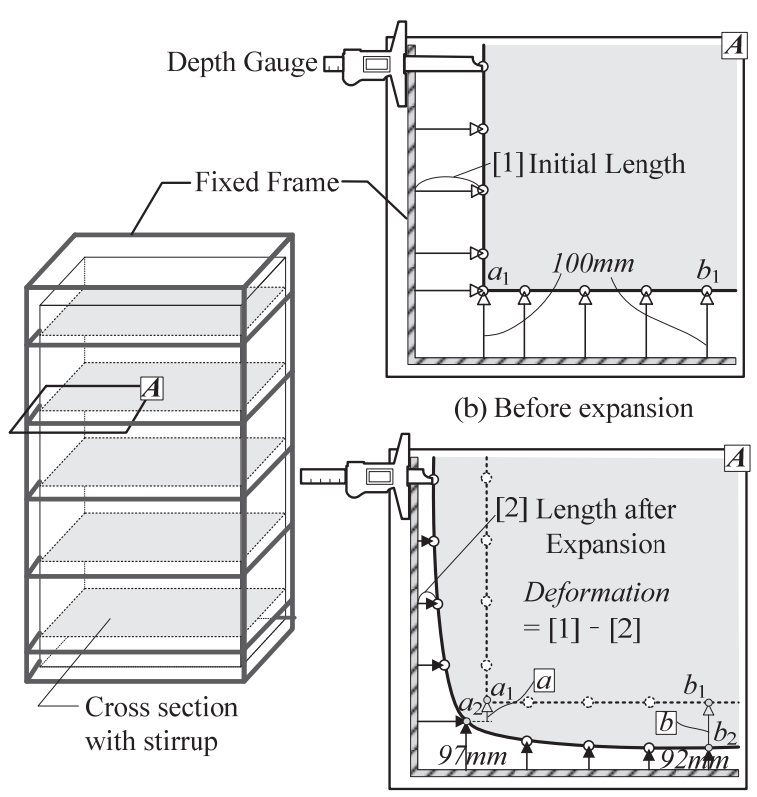

(a) Positions for measurement

(c) After expansion

Fig. 13 Measurement of deformations.

cracking type did not vary between Cases 14 and 16, which suggested that the cracking form was not influenced by parameters. Further, as the generation mechanism, it was considered that the bending effect by greater restraint in the corner induced cracking in the center from exterior. Whereas, the tensile effect from uniform inner expansion caused cracking in the corner to run in the diagonal direction. 


\section{MECHANISM EVALUATION FOR GENERATION OF DEFORMATION}

Regarding Topic 2 (to learn about the casual factors for the deformation condition of the stirrup, the generation mechanism of cracking and deformation was evaluated), features of circular-arc deformation as well as its possible influence on stirrup motion were evaluated.

\section{(1) General deformation conditions}

To understand the deformations in cross-sections of stirrups, Fig. 13 illustrates the measurement method. Cross-sections with the arrangement of five stirrups were the measurement objectives. As shown in Fig. 13(a), a fixed frame was set around each cross-section. To obtain the length from the fixed frame to the concrete surface, the measuring scale was set at a position $40 \mathrm{~mm}$ away from the endpoint of the corner and then followed by each $100 \mathrm{~mm}$ (refer to Fig. 13(b) and 13(c)). From the calculation of the difference in value of the lengths before and after expansion, the deformation was obtained (e.g., by the length difference, vertical deformation from Point $a_{1}$ to $a_{2}$ and from $b_{1}$ to $b_{2}$ is $3.0 \mathrm{~mm}$ and $8.0 \mathrm{~mm}$, respectively). Furthermore, deformation was considered to be composed of uniform elongation and circular-arc deformation. Deformation $a$ (vertical deformation from $a_{1}$ to $a_{2}$, Fig. 13(c)) in the corner point was defined as uniform elongation; while the difference between maximum deformation $b$ (vertical deformation from $b_{1}$ to $b_{2}$, Fig. 13(c)) and deformation $a$ was defined as circular-arc deformation $(5.0 \mathrm{~mm}$ as the difference between 8.0 and $3.0 \mathrm{~mm}$ ).

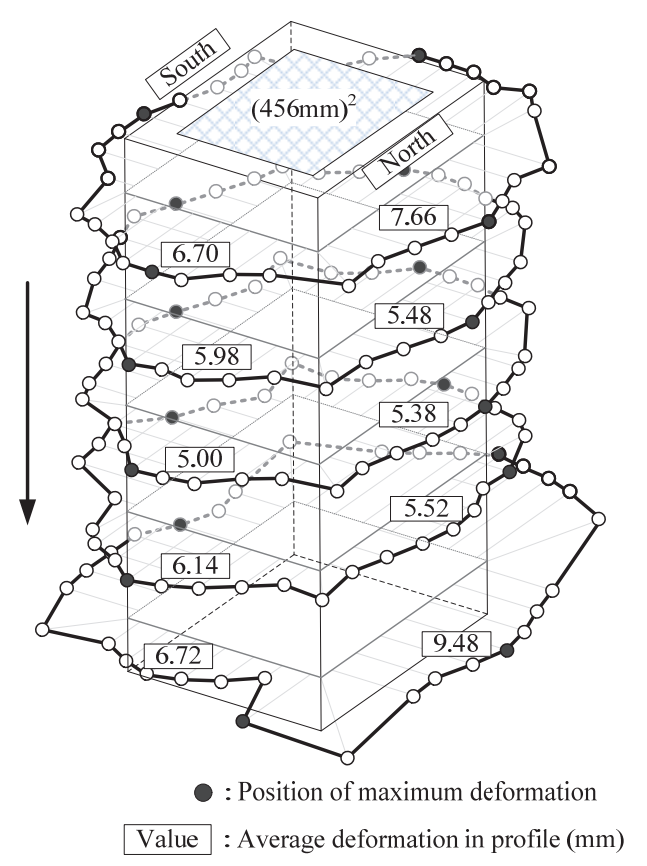

(a) Final (After 24.0hr, Case 14)
Therefore, to understand the general deformation level, the increasing area of the cross-section was evaluated first. As illustrated in Fig. 14(a), increasing area was defined as the difference between the area after expansion and the initial area (initial area as $464200 \mathrm{~mm}^{2}$ and $839056 \mathrm{~mm}^{2}$ for Case 14 and Case 16 (refer to Fig. 5)). From the results shown in Fig. 14(b), it was found that Case 14 had an increasing ratio of area of $3.7 \%$ to be 2.5 times that of $1.5 \%$ for

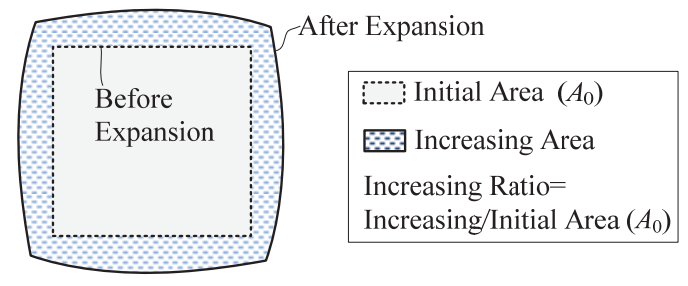

(a) Definition for Area

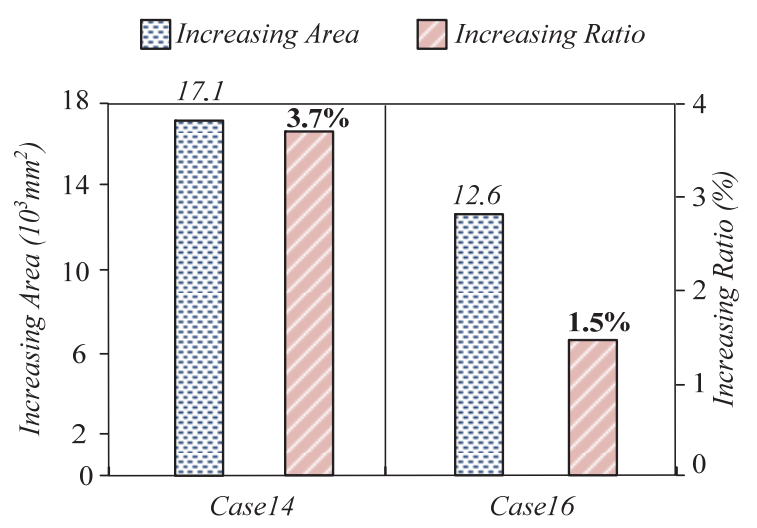

(b) Comparison of Increasing Area

Fig. 14 Comparison of increasing area of cross-section.

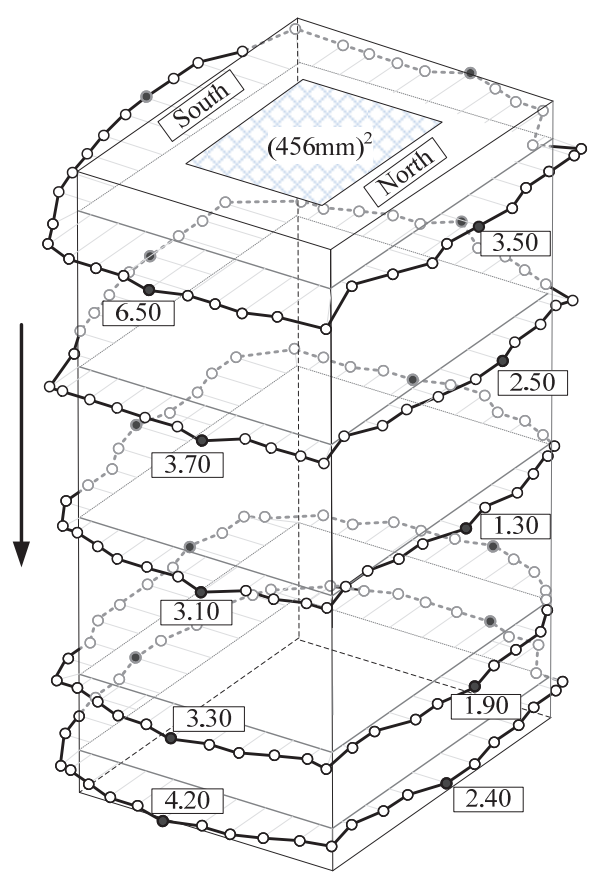

(b) Final (After 7.75hr, Case 16)

Fig. 15 General deformation forms. 


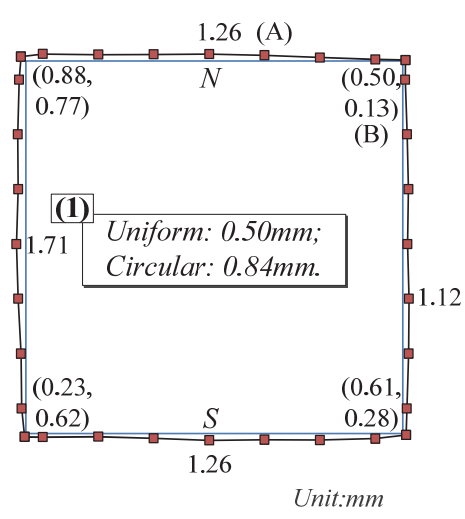

(a) After $8.0 \mathrm{hr}$

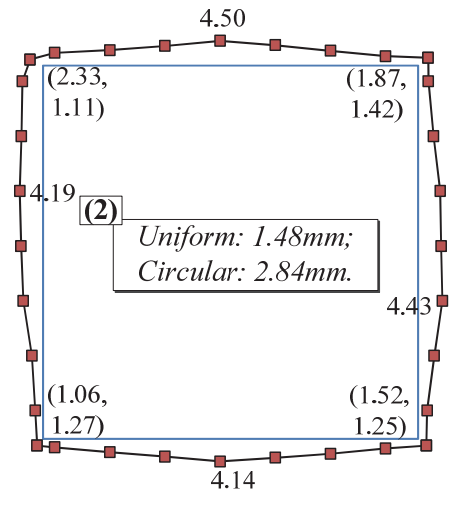

(b) After $10.0 \mathrm{hr}$

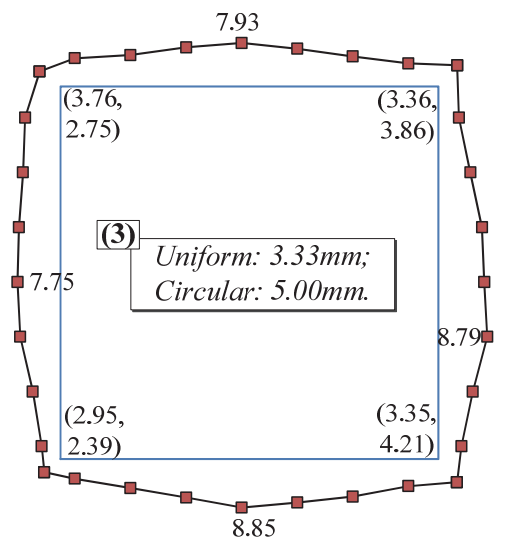

(c) After 24.0hr (Final)

Fig. 16 Time variation for general deformations (Case 14).

Case 16, induced by smaller restraint of frame concrete.

Subsequently, to understand the general deformation forms, final deformations of Case 14 and 16 are shown in Fig. 15. The value illustrated is the average deformation in each profile. As for Case 14 (Fig. 15(a)), deformation increased gradually toward the center area. All cross-sections were confirmed to have circular-arc deformation, which was considered to be very influential on the movement of the stirrup $^{7)}$. Further, in both ends of the specimen (Crosssections 1 and 5), the average deformation had greater values than the other cross-sections, which was due to the easier expansion from lesser restraints of stirrups in both ends. On the other hand, for Case 16 (Fig. 15(b)), as the maximum deformation occurred in the center of the profile, the general circular-arc deformation was also confirmed. Similar to the case described above, deformations in both ends of the specimen were of a greater level. However, deformation values were on a smaller level from greater constraints than Case 14.

Accordingly, it was indicated that similar to the growth of cracking, although the deformation increment was different, a similar deformation form was confirmed.

\section{(2) Time-dependent variation and classification}

To understand the time-dependent features of deformation, the situations of Case 14 are shown in Fig. 16. Here, due to the slight variation in deformation form and values between cross-sections 2,3 , and 4 (refer to Fig. 15(a)), the average deformation in each corresponding point was applied. After $8.0 \mathrm{hr}$ of expansion (Fig. 16(a)), the values in the profile such as A signified the maximum deformation of each profile; while the values in corners such as B mean deformations in the $x$ and $y$ direction of corner points. Thus, uniform elongation was obtained as $0.50 \mathrm{~mm}$ (average of eight values in corners). The average circular-arc deformation was $0.84 \mathrm{~mm}$. Together with

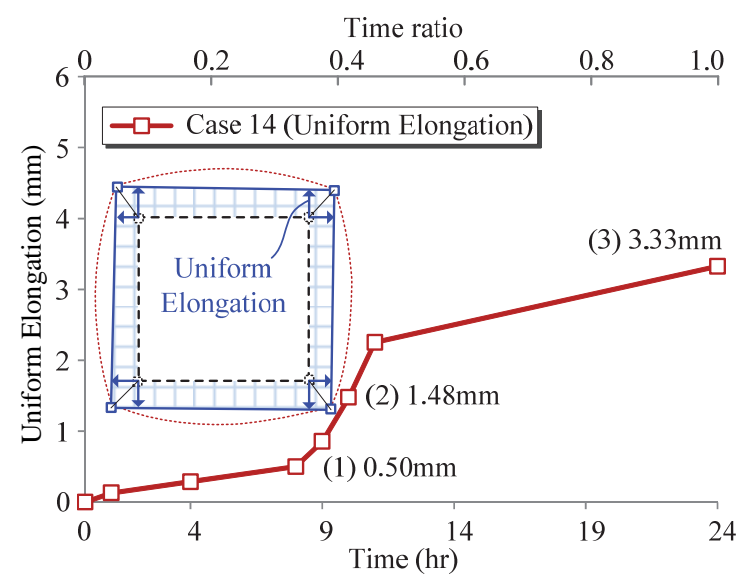

(a) Time variation of uniform elongation

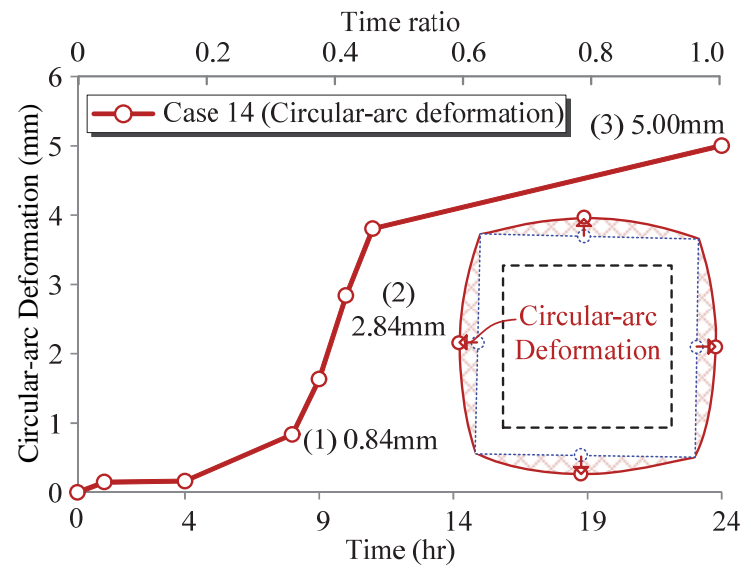

(b) Time variation of circular-arc deformation

Fig. 17 Time variation of classified deformation (Case 14).

further expansion after $10.0 \mathrm{hr}$ (Fig. 16(b)), deformations expanded in general with the maximum in the center of $4.50 \mathrm{~mm}$ while that in the corner varied to be $2.33 \mathrm{~mm}$. Finally, for the ultimate state (Fig. 16(c)), the maximum deformation separately changed to 8.85 and $4.21 \mathrm{~mm}$ in the center and the corner.

To understand the variation trend in classified deformations, Fig. 17 presents the data for each time point. Points (1), (2), and (3) in Fig. 17 correspond to 


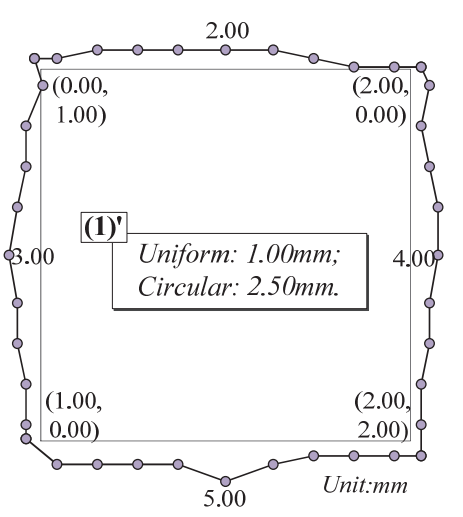

(a) After $2.80 \mathrm{hr}$

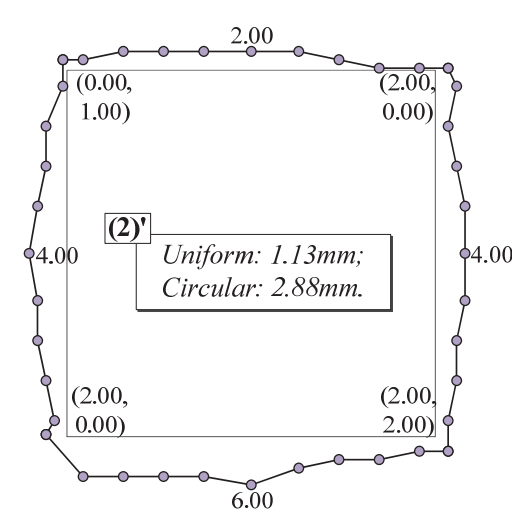

(b) After $3.25 \mathrm{hr}$

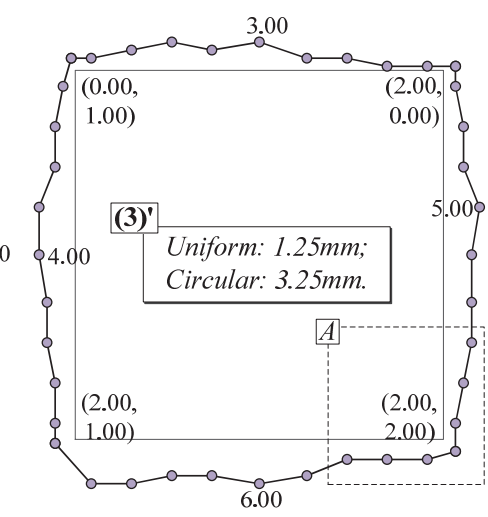

(c) After $7.75 \mathrm{hr}$ (Final)

Fig. 18 Time variation for general deformations (Case 16).

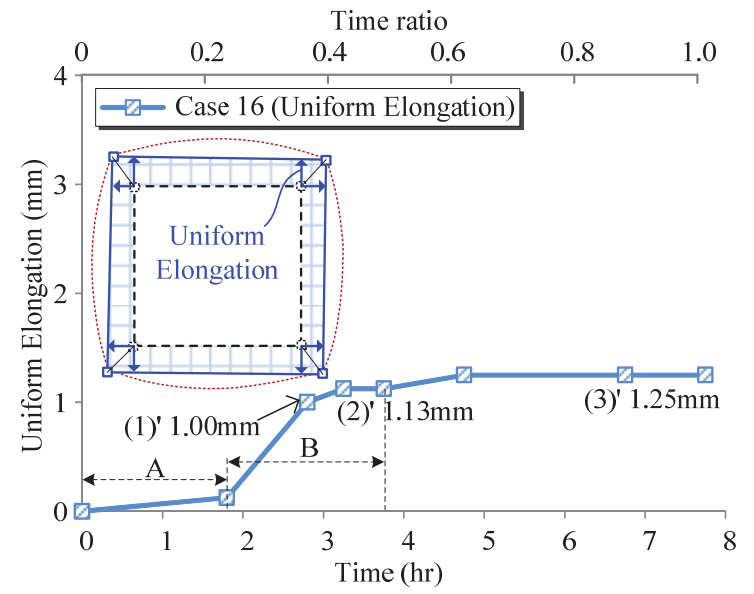

(a) Time variation of uniform elongation

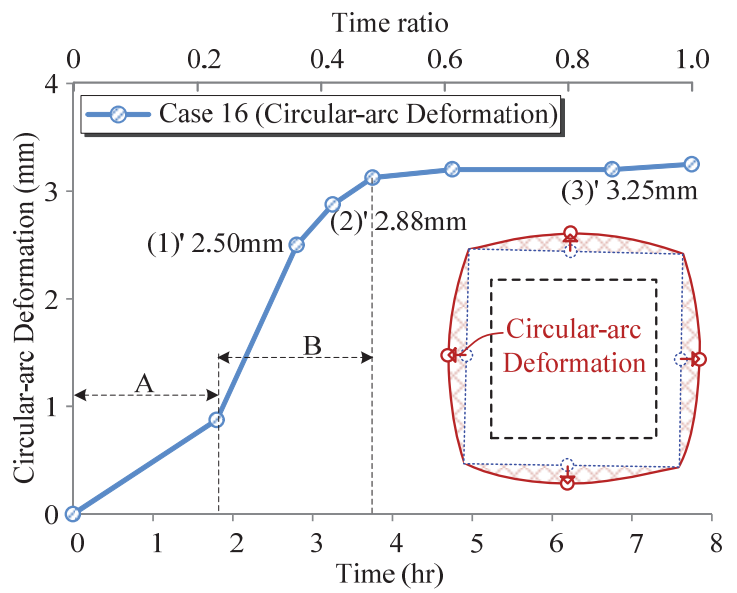

(b) Time variation of circular-arc deformation

Fig. 19 Time variation for classified deformation (Case 16).

those in Fig. 16. As denoted in Fig. 17(a), uniform elongation increased slowly before $8.0 \mathrm{hr}$ (point (1)). Subsequently, as cracking was confirmed to appear in the profile of the specimen (refer to Fig. 9(a)), the rigidity of frame concrete was estimated to decrease and thus deformation showed an intense rise from time point (1). After $11.0 \mathrm{hr}$, the increment of deformation began to decrease. Expansion was supposed to converge after this time point (cracking also had no great variation from $10.0 \mathrm{hr}$ to $24.0 \mathrm{hr}$ (refer to Fig. 9(b) and 9(c))). Finally, the maximum uniform elongation was confirmed as $3.33 \mathrm{~mm}$.

Additionally, as shown in Fig. 17(b), the circulararc deformation had a similar variation trend to uniform elongation. In $24.0 \mathrm{hr}$ (point (3)), circular-arc deformation changed to a maximum of $5.00 \mathrm{~mm}$. Specimens using ASR reactive aggregates were also examined by the authors ${ }^{8)}$. A similar circular-arc deformation near $1.0 \mathrm{~mm}$ was also validated to generate after around 1113 days' outdoor exposure. The current specimen using expansive mortar to simulate the inner expansion was considered to have reproduced the ASR-induced circular-arc deformation being crucial for stirrup raptures.

A comparative study for Case 16 was conducted.
After $2.80 \mathrm{hr}$ of expansion as in Fig. 18(a), deformations were produced with maximum $5 \mathrm{~mm}$ and 2 $\mathrm{mm}$ in the center and the corner, respectively. After $3.25 \mathrm{hr}$ (Fig. 18(b)), the value in the center increased to a maximum of $6 \mathrm{~mm}$ while in the corner it showed no variation. In addition, for the final state $(7.75 \mathrm{hr}$, Fig. 18(c)), general deformation had a slight increment while maximum values remained the same. For each time point, it was clarified that deformation rose from the corner to the center of the profile. Circulararc deformation such as Case 14 grew over time.

Time evolutions for two types of deformation are illustrated in Fig. 19. For contrasting variation trends between Case 16 and Case 14 (Fig. 17), the definition for dimensionless time was applied. The time ratio 1.0 was defined as the end time of expansion to be $7.75 \mathrm{hr}$ for Case 16 and $24.0 \mathrm{hr}$ for Case 14. As denoted in Fig. 19, deformations increased slowly before $1.80 \mathrm{hr}$ (time ratio 0.2 ). After that, values had an intense rise before $3.75 \mathrm{hr}$ (ratio about 0.5 ). Thus, deformations became stable with the maximum value. Additionally, as in Fig. 17, Case 14 also had a smaller increase before $8.0 \mathrm{hr}$ (time ratio 0.3 ) and then intense growth until $11.0 \mathrm{hr}$ (time ratio around 0.5 ) and a slight variation at the end. A similar time variation 
tendency was verified for two cases.

To investigate the reason for this development tendency, the inner temperature measured from Case 16 was evaluated. As shown in Fig. 20, before expansion, a recording thermometer was input in the central point of the cross-section, which was located at $800 \mathrm{~mm}$ from the upper side (central section). Therefore, from reordering the results, it was found that temperature increased dramatically from the initial value of around $37^{\circ} \mathrm{C}$ up to $3.75 \mathrm{hr}$ (time ratio 0.5 ) for the maximum at $106^{\circ} \mathrm{C}$. After that, values began to decrease due to convergence of the reaction.

Thus, in contrast to the deformation progress illustrated in Fig. 19, the great rise of inner temperature corresponded to the intense increase of deformation (Stage B) before $3.75 \mathrm{hr}$ (time ratio 0.5). After that, the decrease of temperature caused reduction of the reaction speed for expansion and thus slowed the development pace of deformation.

\section{(3) Image for the generating mechanism}

With respect to Topic 2, the image for the generation mechanism and its possible connection to stirrup motion are discussed. Distributed load was assumed to act on the frame concrete. The frame part $A B$ (Fig. 21(a)) was the focus and assumed to receive fixed restraint in both ends. Thus, due to the restraint in the corner part, the distributed load in the vertical direction $w_{y}$ produced moment $(M)$ with the distribution imaged in Fig. 21(b). Corresponding maximum deformation $\delta_{m}$ was then generated in the central frame. Further, the distributed load in horizontal direction $w_{x}$ transmitted to part AB and resulted in axial force $(N)$ with uniform distribution as referred to in Fig. 21(b). Similarly, deformation $\delta_{n}$ was yielded. Therefore, it was considered that the circular-arc and uniform elongation correlated with $\delta_{m}$ and $\delta_{n}$, which were generated from the bending and tensile effects, respectively. Moreover, due to greater restraint in the corner from the greater size of frame concrete for Case 16, it was noted that the ratio of circular-arc to uniform elongation was 2.6 (refer to Fig. 19), being greater than the 1.5 of Case 14 (Fig. 17). Thus, greater external restraint was found to induce a larger proportion of circular-arc deformation.

Therefore, greater external restraint caused a greater proportion of circular-arc deformation. Further, as an integral summary of Chapters 3 and 4, it was considered that restraint in the corner induced a bending effect, which promoted cracking in the center generating from the exterior. Correspondingly, circular-arc deformation was produced. Besides, as in Fig. 22, for possible influence on stirrup motion, general circular-arc deformation might be influential on the angular opening of corner stirrup.

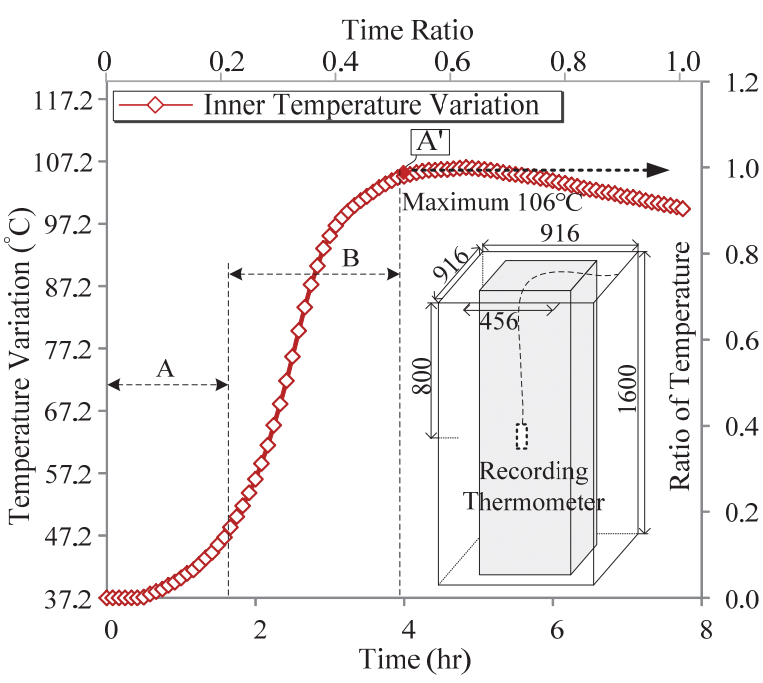

Fig. 20 Time variation of inner temperature (Case 16).

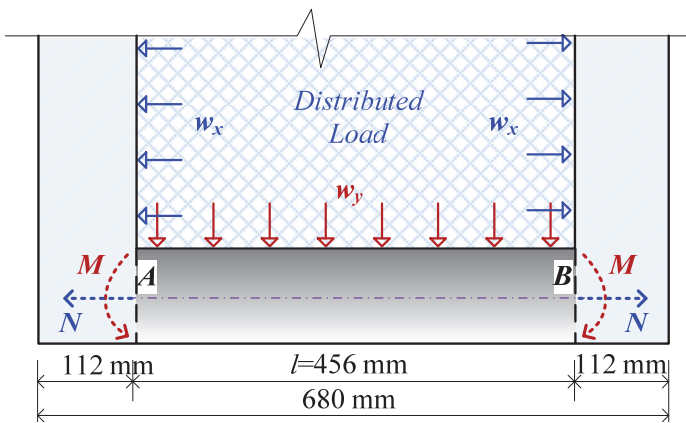

(a) Force Assumption
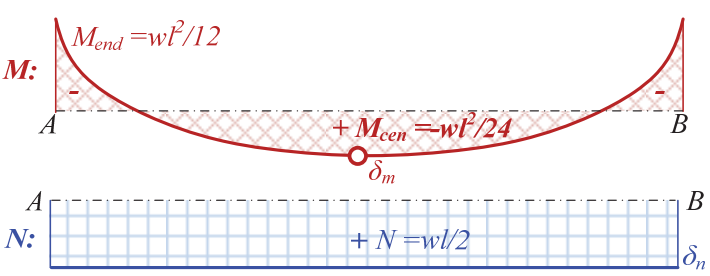

(b) Stress Distributions

Fig. 21 Mechanism for generation of deformations.

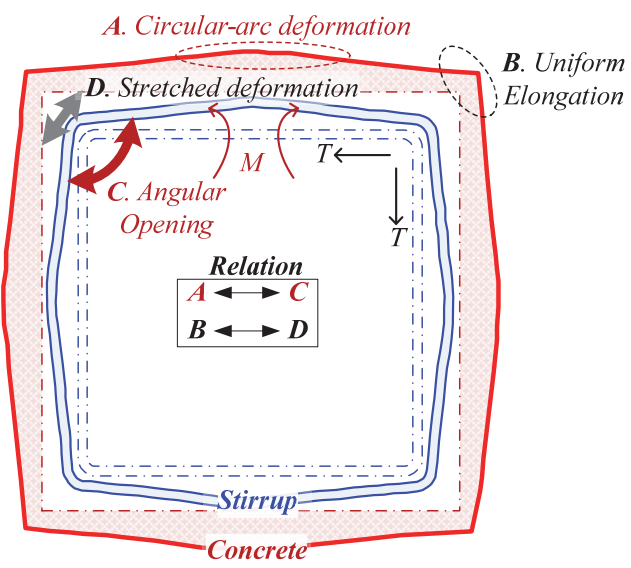

Fig. 22 Image for relation of deformation. 


\section{STUDY OF STIRRUP MOTION DUE TO EXPANSION}

Corresponding to Topic 1 (to understand the real stirrup motion with its influence on the propagation of crack initiation, a study on stirrup performance was conducted), the behavior of a stirrup under expansion is investigated in this chapter.

\section{(1) Movement of corner concrete}

The movement of corner concrete was studied first. Figure 23 shows an example of the measurement method using one corner of Case 16 (A of Fig. 18(c)). As described previously, measuring points were set around the specimen to obtain the deformation. As shown in Fig. 23(a), a coordinate system was established with origin $O$ point in the center of the initial cross-section. Thus, coordinates of measurement points could be obtained. (e.g., (458 mm, $458 \mathrm{~mm}$ ) for the corner point of $A^{\prime}$ in Fig. 23(a)).

As shown in Fig. 23(a), the three measuring points $a, b, c$ were applied for evaluation of the movement features. The initial spacing of $a b$ and $a c$ was 240 $\mathrm{mm}$, being similar to the width of the frame concrete (230 mm, defined as the corner area (refer to Fig. 5(d))). Thus, the initial coordinates were $(458,-458)$, $(218,-458)$, and $(458,-218)$ for Points $a, b$, and $c$, respectively. After expansion, the ultimate state is shown in Fig. 23(b). Based on the deformation values of the measurement points, coordinates for $a, b$, and $c$ separately changed to (461,-460), $(218,-462)$, and $(462,-218)$. As a result, the spacing values of $a b, a c$, and $b c$ were computed as $242.01 \mathrm{~mm}, 243.02 \mathrm{~mm}$, and $346.48 \mathrm{~mm}$, from which, the angle degree of corner concrete was $90.71^{\circ}$ with a $0.71^{\circ}$ increase.

To understand the features of time-dependent movement, Fig. 24 shows the time variation of the angle for the same corner concrete shown in Fig. 23. Similar to the deformation increment (refer to Fig. 19), the angle had an intense increase from $1.80 \mathrm{hr}$ (time ratio 0.2 ). After $4.75 \mathrm{hr}$ (time ratio near 0.6), the angular increment reached maximum at $0.71^{\circ}$. Therefore, it was confirmed that corner concrete generated an angular opening along with inner expansion. Besides, this angular opening was considered to be closely related to the circular-arc deformation of the concrete evaluated in the last chapter.

\section{(2) Movement for bent section of stirrup}

The motion of the stirrup accompanied by the above-mentioned movement behavior was studied. In order to understand the stirrup motion directly, the shapes of the stirrups were recorded before casting expansive mortar and after the end of expansion. The change in angles in the bent section of the stirrups was evaluated. As illustrated in Fig. 25(a), before

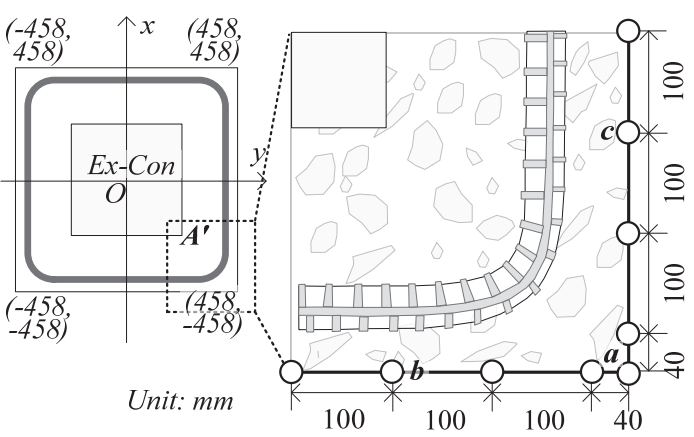

(a). Initial of internal section

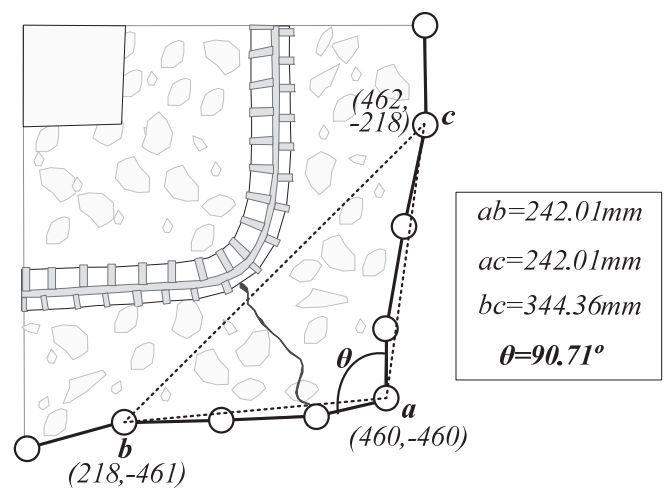

(b). Final of internal section

Fig. 23 Measuring method for angular variation of concrete.

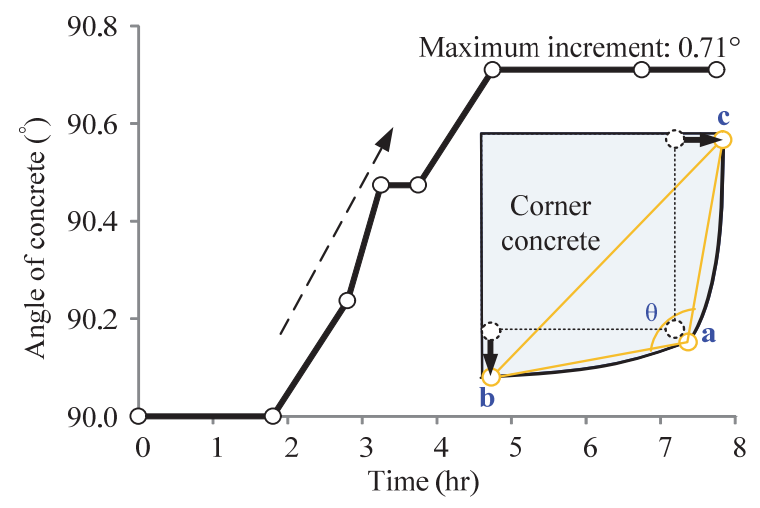

Fig. 24 Time variation of angular increment.

casting the expansive mortar, three points $(o, p, q)$ were selected and marked in the actual stirrup. The spacing value of $o p, o q$, and $p q$ was measured as $92.64 \mathrm{~mm}, 87.86 \mathrm{~mm}$, and $142.43 \mathrm{~mm}$, respectively. Thus, degree $\theta$ for angle poq was obtained as $105.93^{\circ}$. Further, after expansion, the same stirrup was taken out and the spacing value was confirmed separately as $94.91 \mathrm{~mm}, 89.29 \mathrm{~mm}$, and $146.05 \mathrm{~mm}$. Thus, the degree of angle $\theta^{\prime}$ was $107.55^{\circ}$, as shown in Fig. 25(b). The increasing degree of the stirrup was attained as $1.62^{\circ}$, which is the difference.

Applying the same method, 16 corners for old type $\mathrm{B}$ and $\mathrm{C}$ stirrups of Case $16(2 \times 8$ cross-sections, referring to Fig. 5(b) and 5(d)) were measured. From the angular variation results illustrated in Fig. 26, it was confirmed that angle degrees of the stirrup had a 
maximum of $4.22^{\circ}$. Most of the 16 stirrups had an angular increment with an average of $1.85^{\circ}$. The minimum value (Point A of Fig. 26) that occurred for Stirrup B was $-0.34^{\circ}$. This negative value indicated that the corresponding angle changed little after expansion. Therefore, from the increment of the angle in the bent section, it was considered that the stirrup produced an angular opening, which corresponded to the general circular-arc deformation and the angular opening of the corner concrete.

Additionally, crack initiations resulted in a bent section of the stirrup due to the bending process. Therefore, induced by the angular opening of the corner stirrup, crack initiations had great probability of progression. To confirm this estimation, the progression of cracks in stirrups was investigated. Here, the old type C stirrup (Refer to Fig. 5) in which most ruptures occurred was used as a representative. To measure the crack initiation length, six samples were selected from the rebar, which were used for stirrups in the specimen. After the bending process, each sample was cut along the longitudinal direction of the rebar and the crack initiations were observed under a microscope. The average of the maximum crack initiation ratio (ratio of cracking length to stirrup diameter of $16 \mathrm{~mm}$ ) in each test sample was confirmed as 2.56\% shown in Fig. 27.

The progression of cracks in stirrups after expansion was also studied. Type $\mathrm{C}$ stirrups in 18 corners ( 2 corners $\times 5$ sections for Case 14 and 1 corner $\times 8$ sections for Case 16; refer to Fig. 5) were evaluated. Using the same measuring method to the crack initiation, the maximum crack ratio in each corner was plotted in Fig. 27. Induced by the angular opening of corner stirrup, there were two stirrup ruptures (positions (1) and (2) in Fig. 5(a)). Furthermore, compared to the crack initiation ratio of $2.56 \%$, cracking in 11 of a total of 18 stirrups (61\%) progressed with a general average crack ratio after expansion of $17.70 \%$.

Thus, regarding the stirrup motion in Topic 1 , the angular increment of the stirrup was confirmed as $1.9^{\circ}$ to be an average of 16 corners, from which, the angular opening of the corner stirrup was confirmed. Besides, concerning the propagation of stirrup damage in Topic 1, crack initiations progressed from $2.56 \%$ to $17.7 \%$ on average The angular opening of the corner stirrup was considered to be crucial for the progression of crack initiation.

\section{ANALYTICAL CONDITIONS}

Regarding both Topic 1 (to understand the real stirrup motion with its influence on the propagation of crack initiation, the stirrup performance was studied) and Topic 2 (to understand the casual factors of the deformation condition of the stirrup, the generation

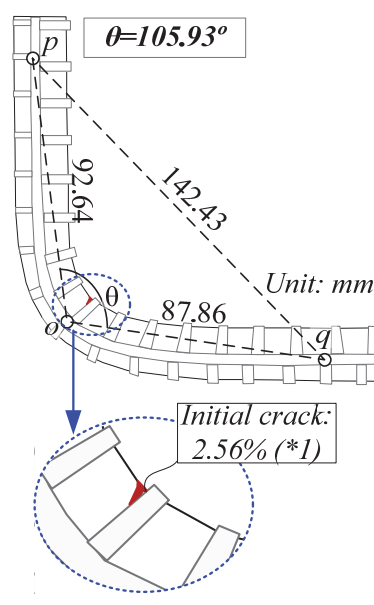

(a). Initial state

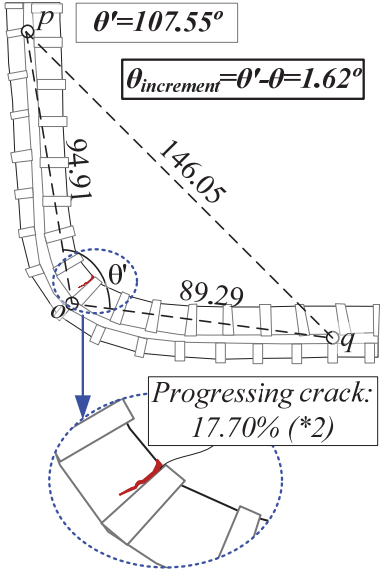

(b). Final state
*1: Average of maximum initial crack ratio in 6 test samples for bending operation;

*2: Average of maximum crack ratio in 18 corner stirrups of specimens after expansion.

Fig. 25 Angular increment of stirrup.

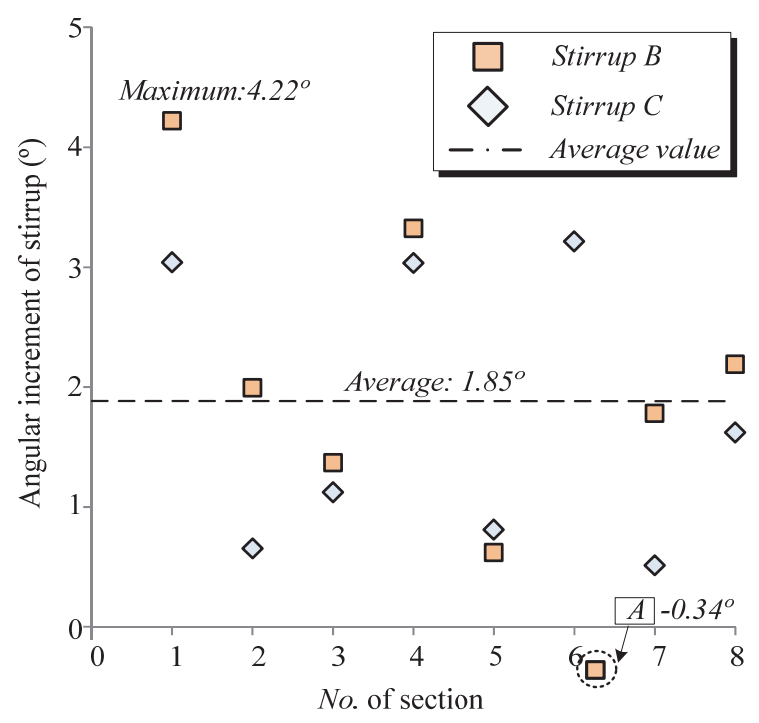

Fig. 26 Distribution for angular increment of stirrup.

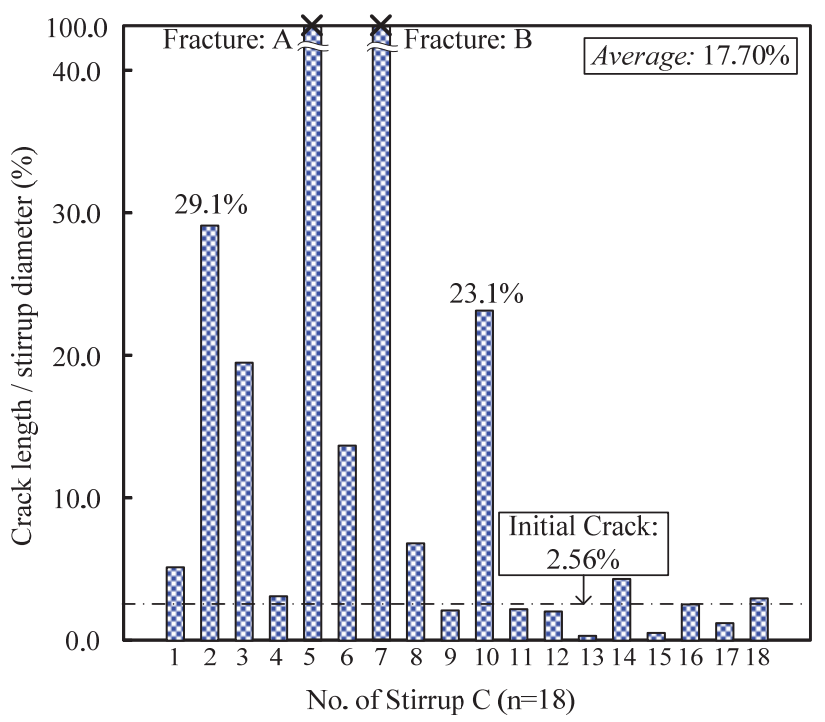

Fig. 27 Progressing of cracks in stirrup. 


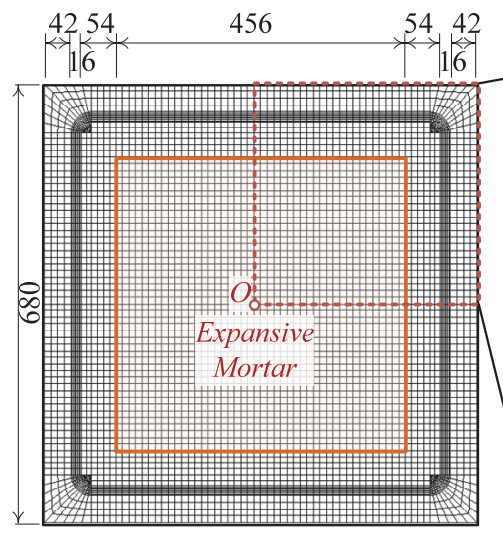

(a) Analysis Model

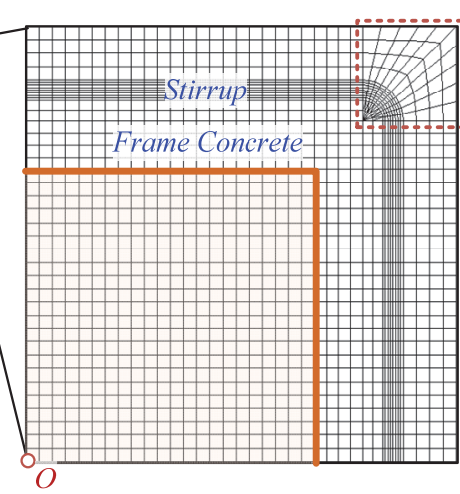

(b) Enlarge of 1/4 Part

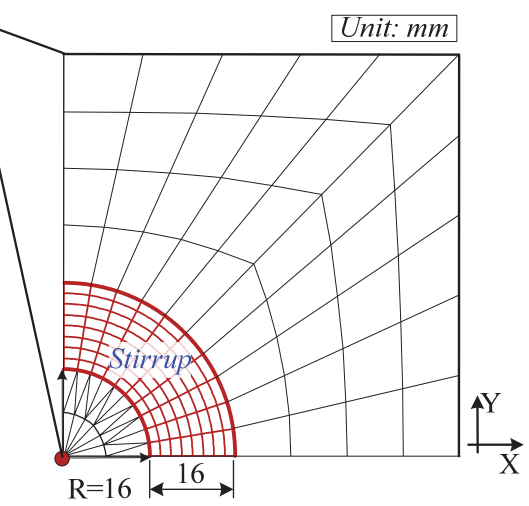

(c) Bent Part of Stirrup

Fig. 28 Analytical models.

mechanism of cracking and deformation was evaluated), analytical evaluations were performed. As preparatory work, the material model for expansive mortar and time history of free expansion were discussed.

\section{(1) Analytical models}

To evaluate the sectional deformation of concrete and the movement behavior of the stirrups, two-dimensional elastic-plastic finite element analysis was conducted. To study the movement features in greater detail, Case 14 was chosen because of the smaller restraint from frame concrete (size of $112 \mathrm{~mm}$; smaller than the $230 \mathrm{~mm}$ of Case 16). The whole section was applied for modeling as shown in Fig. 28(a). Expansive mortar of $456 \mathrm{~mm} \times 456 \mathrm{~mm}$ was simulated. Referring to Fig. 5(a), the spacing of stirrups for Sections $2 \sim 4$ was the same as $285 \mathrm{~mm}$. Thus, for modeling these three sections where most stirrup rupture were confirmed, one stirrup was set into the 2-D model with a depth of concrete model of $285 \mathrm{~mm}$ (refer to (3) of Fig. 5(a) for image; see Section 3). Based on observations from the experiment, expansion in the axial direction was also confirmed. Therefore, four-node quadrilateral isoparametric plane stress elements considering strain in three directions were applied. Point $O$ (Fig. 28(a)) was fixed in $x$, $y$ directions to avoid the shift of the central point. To stimulate the bent section of the stirrup in detail, plane stress elements were also applied (Fig. 28(c)) with a width of $16 \mathrm{~mm}$ (diameter) and a depth of $12.4 \mathrm{~mm}$ (to result in the same area as D16 of $198.6 \mathrm{~mm}^{2}$ ).

Figure 29(a) presents the stress-strain model of frame concrete. On the compression side, a paracurve developed until the compressive strength reached $35 \mathrm{~N} / \mathrm{mm}^{2}$. The Drucker-Prager criterion was used for the biaxial compressive situation. With respect to the tensile side, the curve grew linear to the tensile strength. Then considering the softening condition, the 1/4 model was used. Also, the Rankine criterion was applied. Figure 29(b) describes the stressstrain model for stirrup. The yield and tensile strength

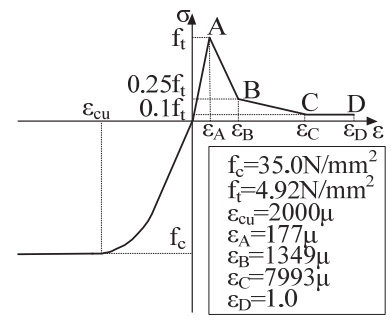

(a) Frame Concrete

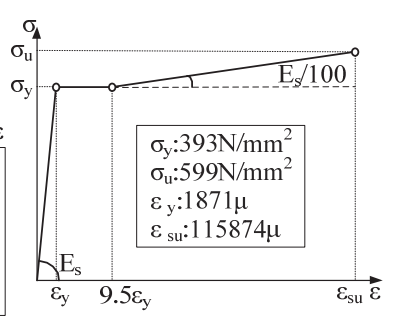

(b) Steel

Fig. 29 Stress-strain for frame concrete and stirrup.

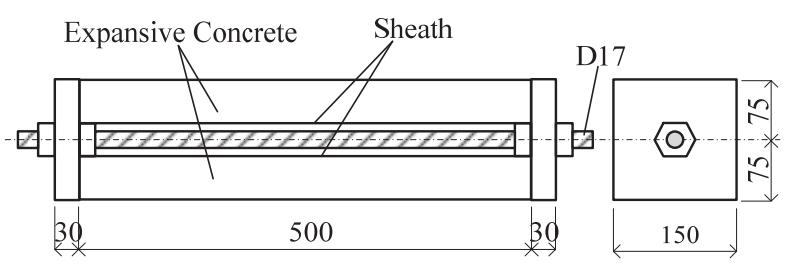

Note: 1) Based on compression test for expansive concrete ${ }^{17}$;

2) Specimen was under water curing for 35days in $20^{\circ} \mathrm{C}$.

Fig. 30 Experimental facilities of specimen for compression test.

was based on values obtained by tensile test. Further, Von-Mises criterion was adopted, and shear stiffness reduction after cracking was implemented with the shear retention factor as 0.2 .

The decision to use the material model of expansive mortar is discussed below. As illustrated in Fig. 30, in the research of Okamura and Tsuji ${ }^{17)}$, specimens of expansive concrete with an amount of expansive agent of $67.5 \mathrm{~kg} / \mathrm{m}^{3}$ and a size of $150 \mathrm{~mm} \times 150$ $\mathrm{mm} \times 500 \mathrm{~mm}$ were manufactured to study the physical properties. In order to prevent adhesion, a sheath was set around the PC steel bar (diameter of $17 \mathrm{~mm}$, restrained ratio around 1.0\%). Expansive concrete was applied in a replacement rate of expansive agent of $0 \%, 13 \%, 15 \%$, and $20 \%$ (replacement rate is the ratio of amount of expansive agent to the sum of amount of expansive agent and cement). After 35 days' water curing at $20^{\circ} \mathrm{C}$, the PC steel bar was removed to relieve the restraint. Then, a compression test was immediately conducted for the specimen 
while it was hardening. The result of the case with a replacement rate of $20 \%$, which was approaching $25.8 \%$ of the current specimen (Table 2), was examined. As the dotted line illustrates in Fig. 31, the maximum strength and corresponding strain were obtained at around $17 \mathrm{~N} / \mathrm{mm}^{2}$ and $1600 \mu$ with the elastic modulus of $10625 \mathrm{~N} / \mathrm{mm}^{2}$.

According to $\mathrm{Wu}$ et al. ${ }^{18)}$, the same lime-type expansive agent as that used in the current specimen was applied and the unit amount was varied from $49 \sim 146 \mathrm{~kg} / \mathrm{m}^{3}$. Unrestrained cylinder specimens of $\Phi 100 \mathrm{~mm} \times 200 \mathrm{~mm}$ were made. After 13 days' water curing at $20^{\circ} \mathrm{C}$, compression tests were conducted and the results are plotted in Fig. 32. From $49 \mathrm{~kg} / \mathrm{m}^{3}$ to $146 \mathrm{~kg} / \mathrm{m}^{3}$ of the expansive agent, compression strength decreased linearly from near $70 \mathrm{~N} / \mathrm{mm}^{2}$ to around $1 / 10$ times at $7 \mathrm{~N} / \mathrm{mm}^{2}$. Thus, despite different restraint conditions, physical factors are fairly small for the current specimen using an amount as large as $200 \mathrm{~kg} / \mathrm{m}^{3}$. Accordingly, as shown in Fig. 31, 1/10 of the previously obtained elastic modulus and strength is selected as instance for the model of expansive mortar, since slight difference in the deformation behavior has been noticed when using small ratio as $1 / 5$, $1 / 10$, or $1 / 20$.

In addition, to simulate the time-dependent expansion in the model, the inner temperature in the specimen was measured. As shown in Fig. 20 (Case 16), the time variation of the inner temperature was recorded. Learning from the general consistency between variation trends of the inner temperature and deformations (refer to Section 4. (2)), and the similar trend shown in previous research ${ }^{19}$, history of inner temperature was non-dimensionalized and used for the variation in thermal expansion acting on the model of expansive mortar (Fig. 28). The coefficient of expansion of $1.0 \times 10^{-5} /{ }^{\circ} \mathrm{C}$ was applied.

Figure 33 shows the results of maximum free expansive strain for expansive concrete, from the experimental tests of Wu et al. ${ }^{18)}$. The unrestrained rectangular columns of $100 \mathrm{~mm} \times 100 \mathrm{~mm} \times 400 \mathrm{~mm}$ were manufactured and cured under water at $20^{\circ} \mathrm{C}$ for 13 days. As illustrated in Fig. 33, the maximum free expansive strain was around $21000 \mu$ when the unit amount was $146 \mathrm{~kg} / \mathrm{m}^{3}$. Further, learning from the approximate linear relation between strain and unit amount, the corresponding maximum free expansive strain is estimated as roughly around $30000 \mu$ using different extrapolation methods for the $200 \mathrm{~kg} / \mathrm{m}^{3}$ in current specimen. The experimental tests used a relatively great amount of expansive agent and provided reliable data. Thus, although under different curing conditions, the estimated maximum free expansive strain of $30000 \mu$ was adopted for the current specimen for the general evaluation. Furthermore, expansion was considered to be terminated after Point $\mathrm{A}^{\prime}$ of

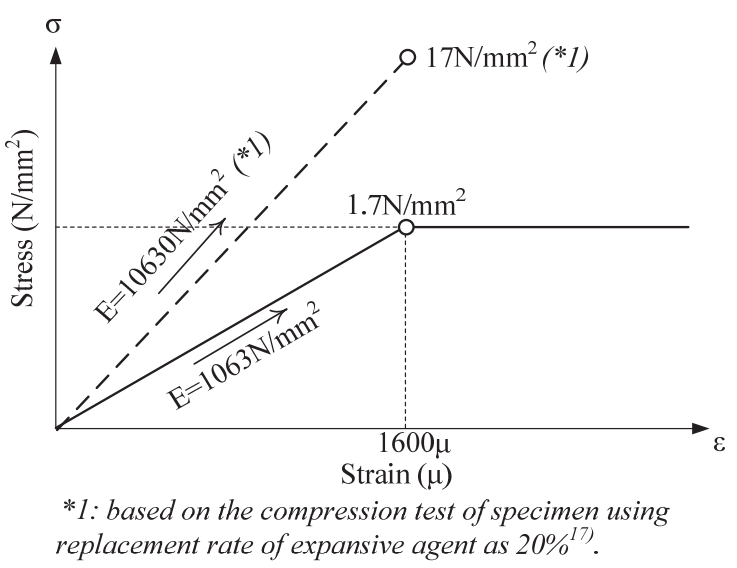

Fig. 31 Stress-strain for expansive mortar.

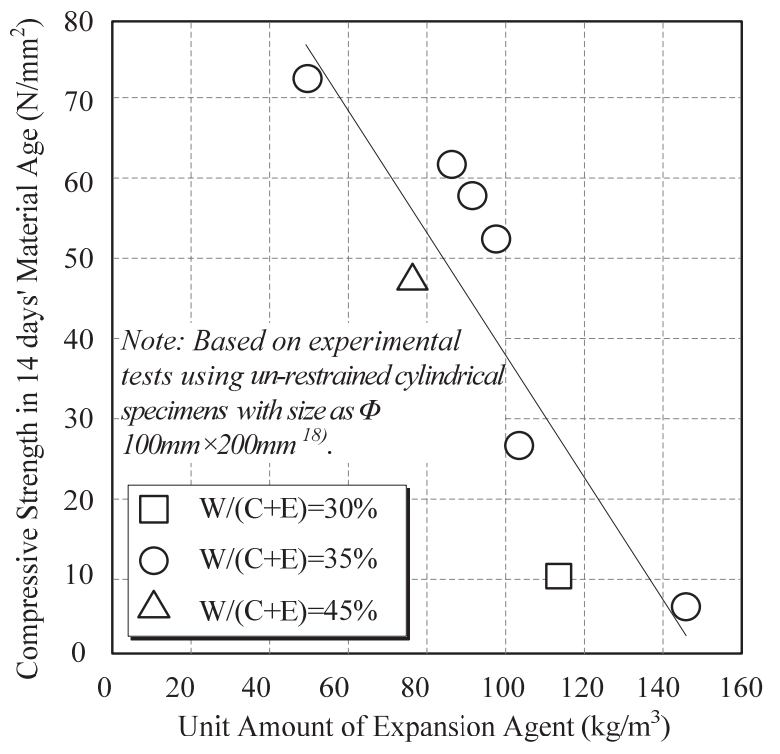

Fig. 32 Variation of physical factors.

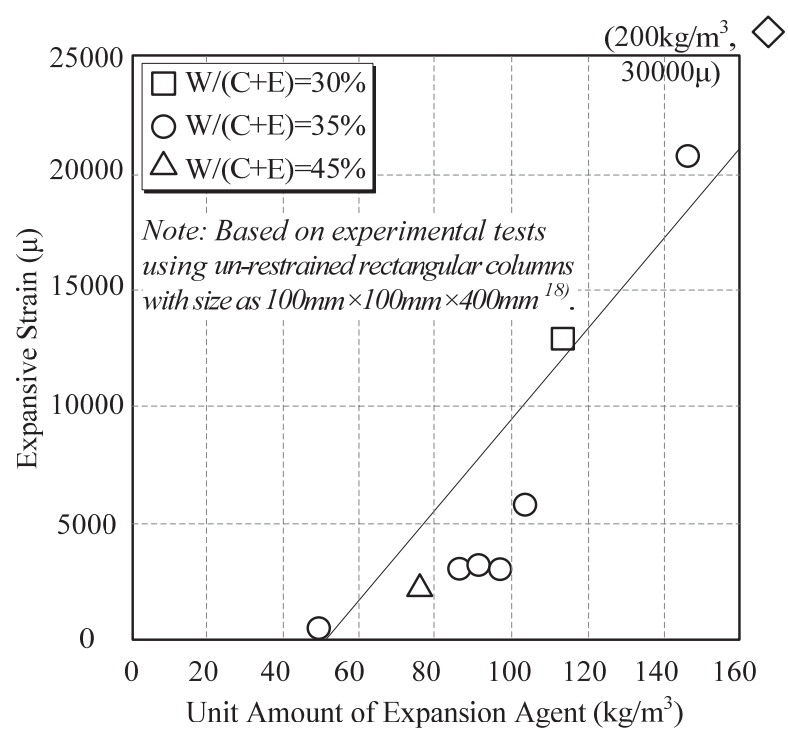

Fig. 33 Maximum free expansive strain. 
Fig. 20 due to the decrement of temperature. The strain was set constantly after the maximum (A') for convergence in analysis.

Therefore, due to a dramatic decline in strength with increment in the amount of the expansion agent, the physical factors as $1 / 10$ of those from the specimen using the same replacement rate of the expansion agent were applied in the model of expansive mortar. Further, the minimum principal stress of $3 \mathrm{~N} / \mathrm{mm}^{2}$ obtained from the analysis is confirmed to be close to the upper limit of those from specimens using different amount of ASR reactive aggregates and alkali contents ${ }^{20)}$.

\section{ANALYTICAL RESULTS}

Concerning both Topic 1 (to understand the real stirrup motion with its influence on propagation of crack initiation, a study on the performance of the stirrup was conducted) and Topic 2 (to understand the casual factors for the deformation condition of the stirrup, the generation mechanism of cracking and deformation was evaluated), the generation mechanism of deformation and stirrup motion were studied numerically. Further, in greater deformation level, Case 14 was the main study objective for analytical evaluation. However, since only the stirrup motion of Case 16 was recorded in experiment, the estimated experimental stirrup motion of Case 14 from Case 16 was also applied in the current study.

\section{(1) Comparison to experimental results}

Here, the deformation behavior, which has the biggest effect on stirrup motion, was examined. Figure 34 shows a comparison of external deformations between the analysis and the experiment in the final state at $24.0 \mathrm{hr}$ of expansion for Case 14. The values shown in Fig. 34 possess the same meanings as those in Fig. 16. Thus, concentrating on the center area, the maximum deformation generated was $8.85 \mathrm{~mm}$ in the experiment, which was similar to the $7.35 \mathrm{~mm}$ in the analysis. Further, for the corner area, the values of the experiment varied from 2.39 to $4.21 \mathrm{~mm}$, being slightly greater than the $2.69 \mathrm{~mm}$ of the analysis. A similar circular-arc deformation form was reproduced by analysis.

Applying the definitions of classification for the deformations described in Fig. 13, a comparison of uniform elongation as the deformation in the corner point is illustrated in Fig. 35. In the experiment, the deformation value was observed to have an acute increment in the initial state and thus a smaller rise after around $11.0 \mathrm{hr}$ due to the convergence of reaction. A similar time variation trend was generated with the maximum uniform elongation of $3.33 \mathrm{~mm}$ and 2.69 $\mathrm{mm}$ for the experiment and analysis, respectively. A

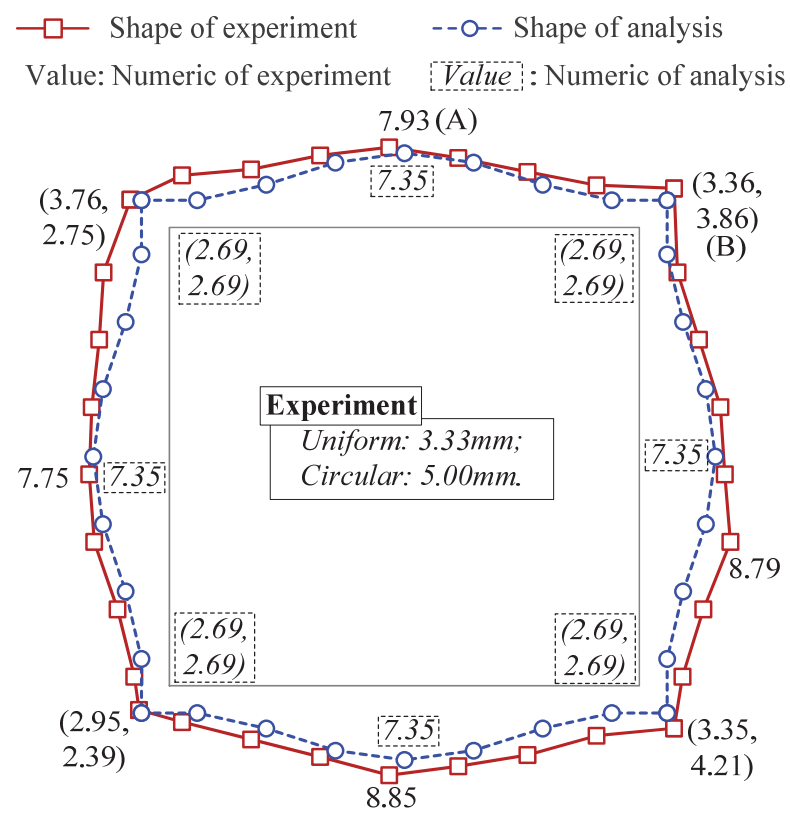

Fig. 34 Comparison of deformation shapes (final state).

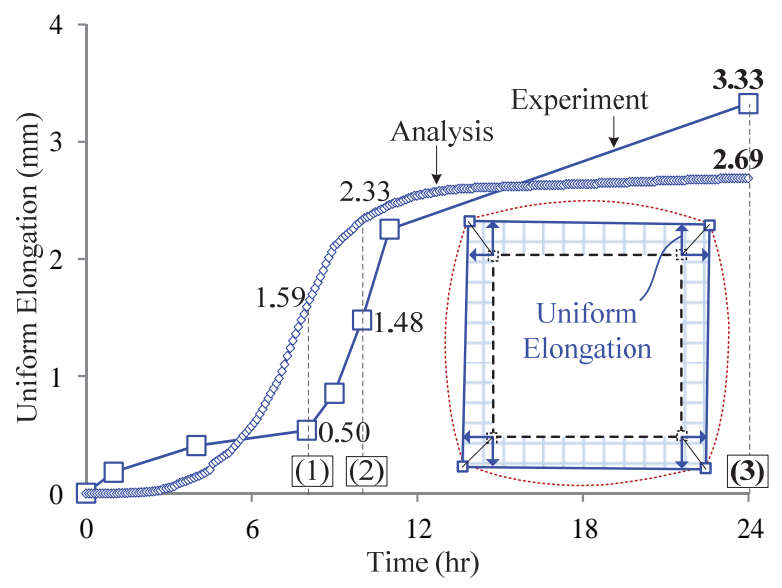

Fig. 35 Time variation of uniform elongation.

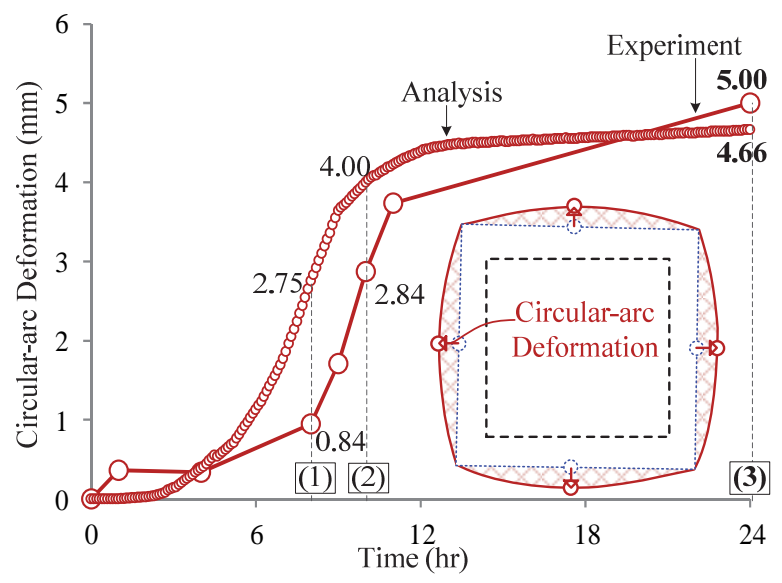

Fig. 36 Time variation of circular-arc deformation. 


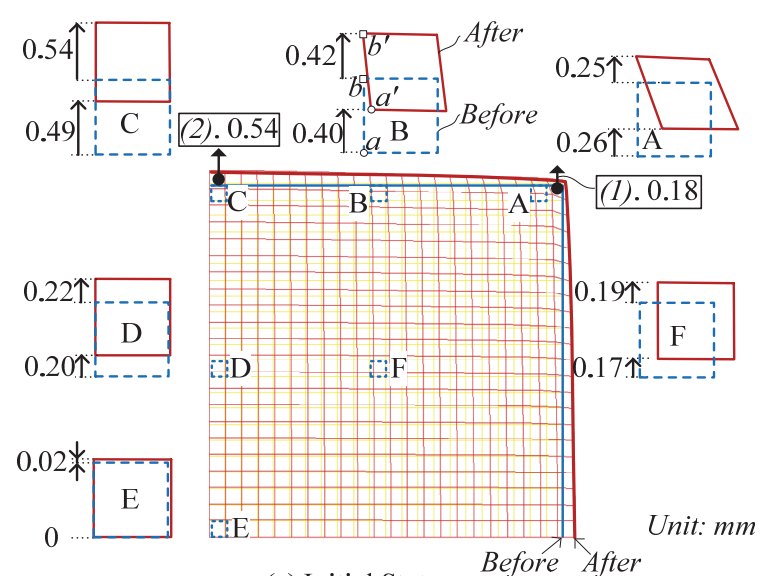

(a) Initial State

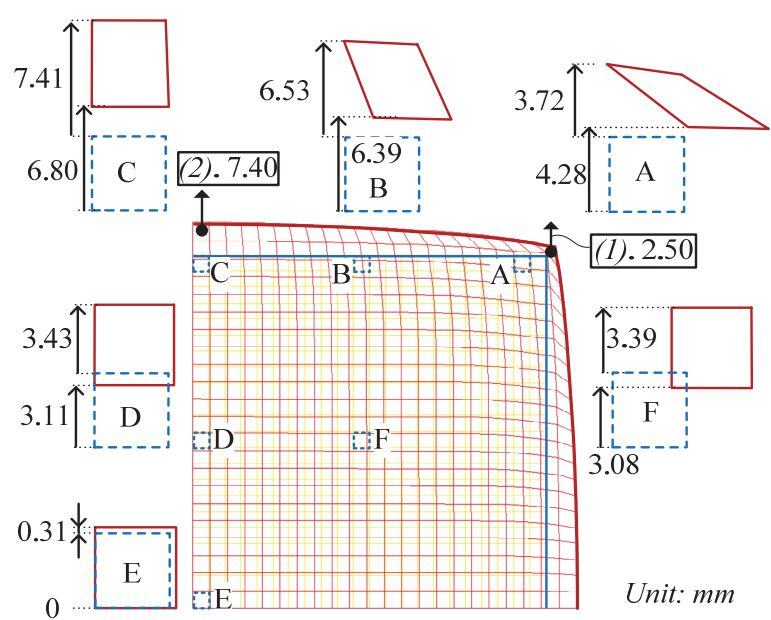

(b) Final State

Fig. 37 Deformation of inner expansive mortar.

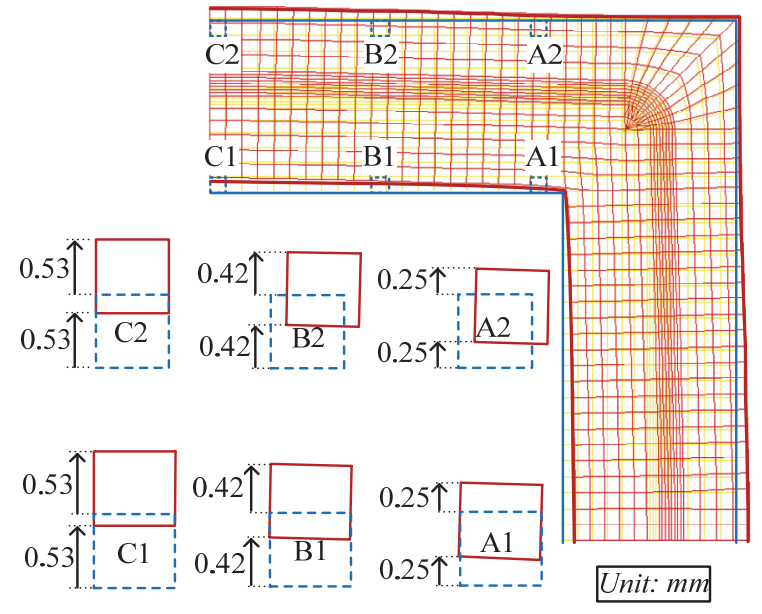

(a) Initial State

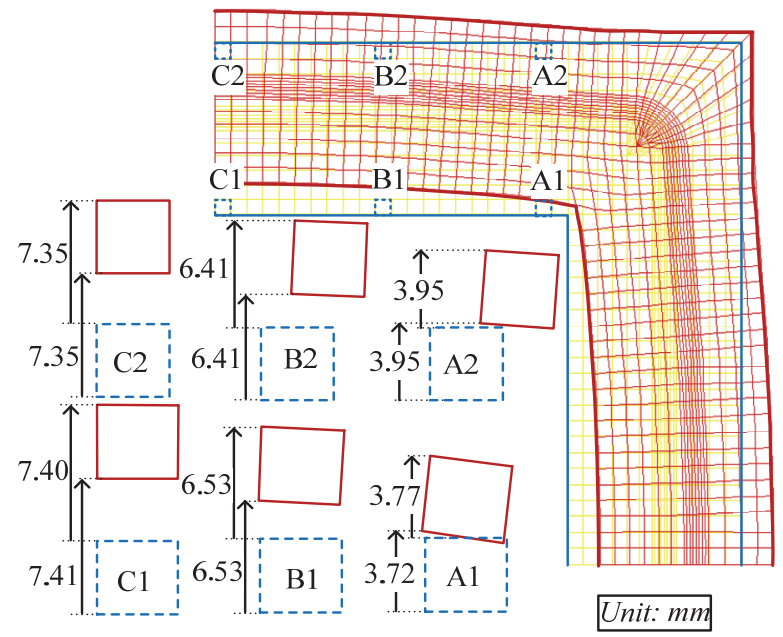

(b) Final State

Fig. 38 Deformation of frame concrete.

comparison of circular-arc deformation is shown in Fig. 36. Close time variation trend was also obtained between analysis and experiment. Further, the maximum circular-arc deformation was $4.66 \mathrm{~mm}$ for analysis near $5.00 \mathrm{~mm}$ of the experiment.

In addition, regarding the difference in deformation values between the analysis and the experiment such as in point (1) for $8.0 \mathrm{hr}$ and (2) as $10.0 \mathrm{hr}$ of expansion (Fig. 35 and Fig. 36), variation in deformation from the experiment seemed to have a small time lag contrasted to that of the analysis, which was based on the time history of the inner temperature. This slight time lag could also be inferred between the inner temperature and the expansion from the test of the expansive agent ${ }^{19)}$. However, viewing the roughly identical time variation trend and the similar ultimate deformation values, the analysis was considered to have roughly reproduced the movement behavior of concrete.

\section{(2) Generating mechanism of deformations}

In this section, the generation mechanism of the external deformation is explained. To process the essential evaluation, the deformation behavior of the inner expansive mortar as the motive power of expansion was examined. Figure 37(a) illustrates the deformation conditions for $1 / 4$ cross-section of expansive mortar in the initial state $(4.0 \mathrm{hr}$ of expansion for instance). Figure 37(b) demonstrates that of the final state (24.0 hr of expansion). Thus, as shown in Fig. 37(a), general circular-arc deformation was produced for the expansive mortar. Moreover, due to the symmetry, six elements named from A to F were adopted as representatives to study the movement in detail. Elements displayed by dotted and solid lines show the situation before and after expansion, respectively. In addition, the value illustrated in the figure signifies the vertical deformation for node points in the left side of the element. Take element B in Fig. 37(a) as an example, 0.40 and $0.42 \mathrm{~mm}$ is separately the vertical deformation for Points $a$ and $b$.

Thus, as to element D in Fig. 37(a), the deformation values in the node points were confirmed as 0.22 and $0.20 \mathrm{~mm}$. From the difference, the element 
length was increased by $0.02 \mathrm{~mm}$. Similarly, the same increment of element length as $0.02 \mathrm{~mm}$ was also verified for elements $E$ and $F$. Hence, a uniform increment in element length due to expansion was validated and this is considered to be responsible for generating the uniform tension in frame concrete and thus the uniform elongation.

Additionally, with respect to element $\mathrm{C}$ in Fig. 37(a), the increment in element size was validated to be $0.05 \mathrm{~mm}$ from the difference of its deformations of 0.54 and $0.49 \mathrm{~mm}$. However, the change in element length was as small as $0.02 \mathrm{~mm}$ and $-0.01 \mathrm{~mm}$ for elements B and A, respectively. Due to the decrease in confinement by the stirrup from the corner to the center area, the expansion becomes much easier from element A near the corner toward element $\mathrm{C}$ in the center. Therefore, this difference in expansion level from the corner to the center was supposed to be responsible for the production of bending action in the frame and for the circular-arc deformation. With regard to Fig. 37(b) for the final state, the general circular-arc deformation of expansive mortar becomes more distinct. Furthermore, the uniform increment in length of around $0.31 \mathrm{~mm}$ was confirmed for elements D, E, and F; while the difference in length variation was also found for elements $\mathrm{A}$ to $\mathrm{C}(-0.56 \mathrm{~mm}$ for $\mathrm{A}, 0.14 \mathrm{~mm}$ for $\mathrm{B}$, and $0.61 \mathrm{~mm}$ for $\mathrm{C})$. In general, regarding (1) and (2) of Fig. 37(b), owing to the effective confinement of the stirrup in the corner area, expansion was relatively small (average increment in element size of $0.11 \mathrm{~mm}, 2.5 \mathrm{~mm}$ in total for 22 elements). Whereas, owing to the weak confinement of the stirrup in the central area, maximum expansion resulted (average increment of element size of 0.34 $\mathrm{mm}$, totaling $7.4 \mathrm{~mm}$ for 22 elements).

Subsequently, to study the corresponding movement conditions of frame concrete together with that of the inner expansive mortar, a similar evaluation was conducted for frame concrete as illustrated in Fig. 38. Corresponding to the elements A, B, C in expansive mortar (Fig. 37), six elements were selected in the frame. For example, A1, A2 in Fig. 38(a) are located separately in the bottom and top line of the frame within the same row as element A of the expansive mortar in Fig. 37(a). Thus, concentrating on the initial state in Fig. 38(a), it can be seen that circular-arc deformation was generated for the general frame likewise to the expansive mortar (Fig. 37(a)). As to element C1 in Fig. 38(a), the deformation was identical to the $0.53 \mathrm{~mm}$ in the node points. The same situation was also verified for the other five elements. Thus, there was no variation of element length for the frame part. Further, the maximum deformation of $0.54 \mathrm{~mm}$ of element C (Fig. 37(a)) was transferred to $\mathrm{C} 1, \mathrm{C} 2$ in the frame of around $0.53 \mathrm{~mm}$ (Fig. 38(a))

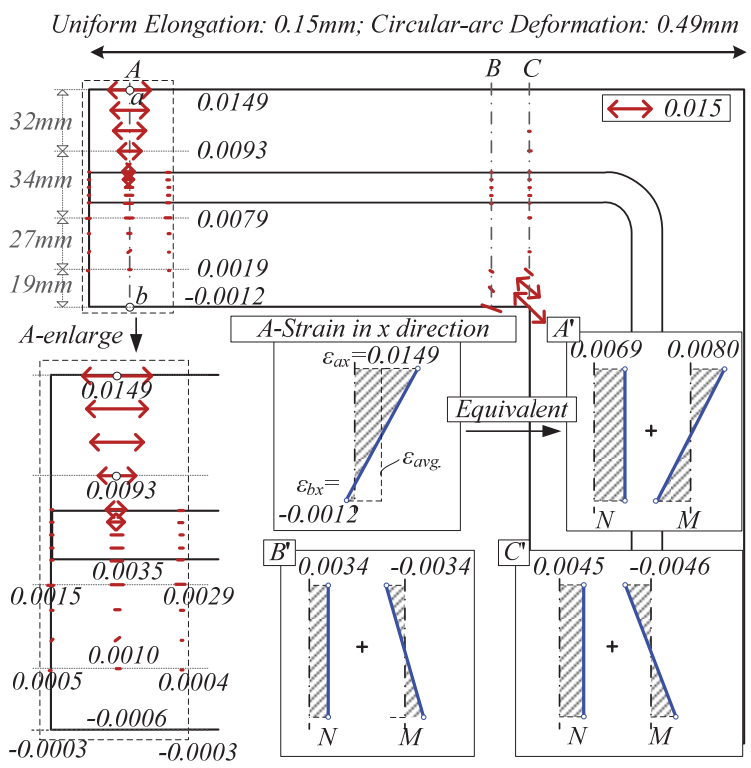

(a) Initial State

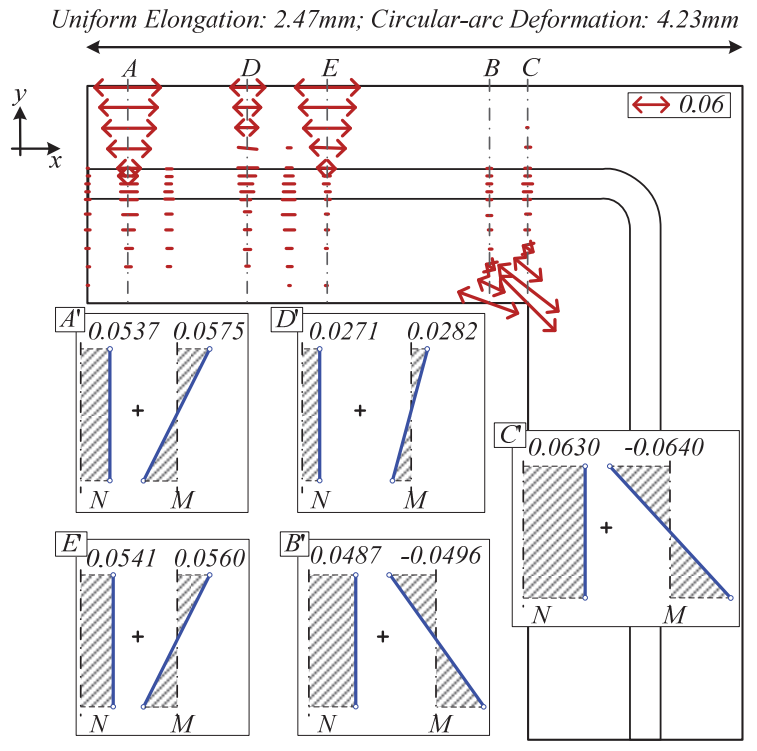

(b) Final State

Fig. 39 Strain distributions in frame concrete.

without a big change. Hence, deformation of the element in expansive mortar was transferred to the element in the frame entirely. Besides, for the final state in Fig. 38(b), the general circular-arc deformation of the frame became more obvious. In accordance with the initial state, the element length was hardly varied because of similar deformation values in node points. Moreover, the deformation from the element in expansive mortar was directly delivered to those in the frame (the maximum deformation of $7.41 \mathrm{~mm}$ of the element C (Fig. 37(b)) was transferred to C1, C2 in the frame of 7.41 and $7.35 \mathrm{~mm}$ (Fig. 38(b)).

To check the actual effects acting on frame concrete corresponding to the behavior of the inner expansion, the strain distributions were studied. Vectors of maximum principal strain (such as Section A in 
Fig. 39(a)) in the central frame of the $1 / 4$ cross-section were examined. Figures 39(a) and 39(b) illustrate the initial and the final state, respectively. Therefore, for the initial state in Fig. 39(a), great strain mainly generated around Sections A to C, which suggests the occurrence of cracking. For numerical evaluation, detailed strain distribution in the $x$ direction was studied. The strain here was the value in the nodal point, which is the average of the extrapolation strains from Gaussian integral points nearby. Around Section A of Fig. 39(a), the general value was almost linearly changed from 0.0149 in the top line $(\varepsilon a x)$ to -0.0012 in the bottom line $(\varepsilon b x$, sum of great values nearby as shown in A-enlargement of Fig. 39(a)). Thus, as in A' of Fig. 39(a), strains were divided into two parts: those from tensile effect ( 0.0069 as average of 0.0149 and -0.0012$)$ and those from bending effect $(0.0080$ as $1 / 2$ for the difference between them). For Sections B and C (refer to B' and $\mathrm{C}^{\prime}$ in Fig. 39(a)), a similar form is confirmed while the strain from bending in upper section was negative due to the minus moment that occurred as a result of the greater restraint in the corner part.

As to the final state in Fig. 39(b), the strains in Sections $\mathrm{A}$ to $\mathrm{C}$ have obvious increment due to the inner expansion. Further, great strain fields were confirmed to newly occur at Sections D and E in the center area of the frame. Compared to the initial state in Fig. 39(a), although with increment of strain values and strain area for the final situation, strains could also be classified by those from bending action and tensile action (refer to $\mathrm{A}^{\prime}$ to $\mathrm{E}^{\prime}$ ).

To further evaluate the generation mechanism, the inverse computations from strains were conducted as shown in Fig. 40. The final state with larger strain values was used as a representative. As shown in Fig. 40(a), strains from the tensile effect ( $N$ of Fig. 39(b)) in five sections were summed to be $0.247(0.0537$ for A, 0.0271 for D, 0.0541 for E, 0.0487 for B and 0.0630 for $\mathrm{C}$ ). From the product of the summed strain and equivalent length (determined as $10 \mathrm{~mm}$ based on element size), it was found that deformation from tensile effect was $2.47 \mathrm{~mm}$, which is close to the uniform elongation of $2.69 \mathrm{~mm}$ (Fig. 35). Additionally, both the positive bending effect ( $M$ in Fig. 39(b)) in Sections A, D, E and the negative bending effect in $\mathrm{B}, \mathrm{C}$ were considered to promote the generation of flexural deformation. Thus, the average strain distribution was computed for those of Sections A, D, E (Eaverage 1 ) and for Sections B, C (Eaverage 2 ) as shown in Fig. 40(b). Based on the elevation angle $\left(\theta_{1}, \theta_{2}\right)$ of the average strain distributions, their sum was obtained and multiplied by half of the side length for expansive mortar of $228 \mathrm{~mm}$. Thus, the corresponding deformation was $4.23 \mathrm{~mm}$, which was similar to the circular-arc deformation of $4.66 \mathrm{~mm}$.
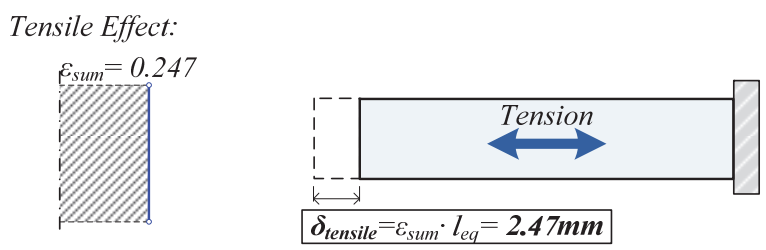

(a) Tensile Effect

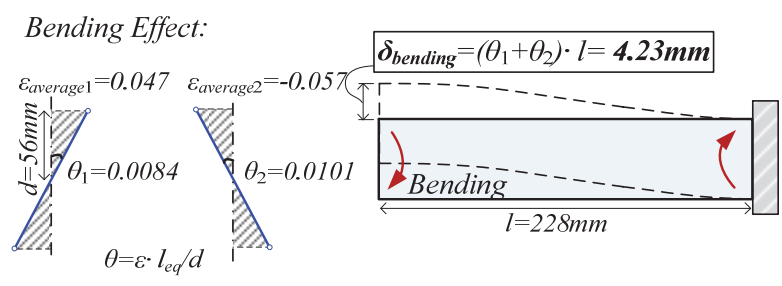

(b) Bending Effect

Fig. 40 Inverse computations from strain.

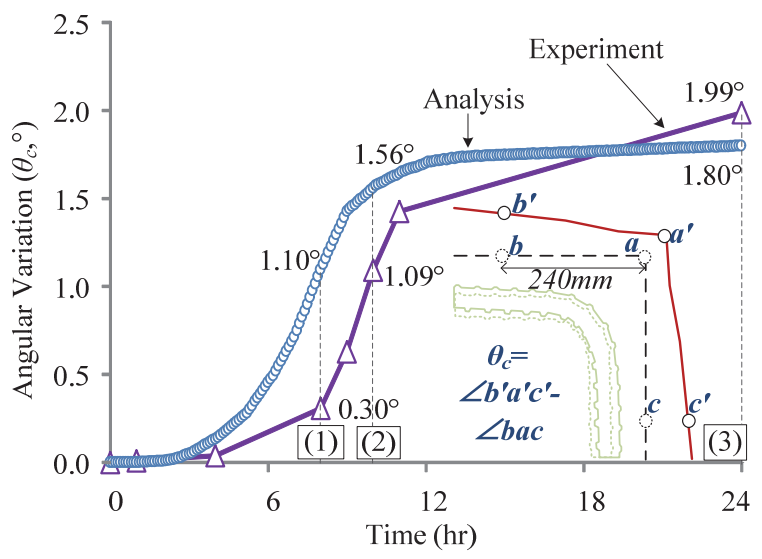

Fig. 41 Time variation of angular change.

In conclusion, uniform expansion in the inner side of expansive mortar was confirmed, which was considered to be responsible for generation of the uniform tension and the deformation of uniform elongation. Further, owing to the effective confinement of the stirrup in the corner and weak confinement in the center area, a difference in expansion in different areas was produced, which further induced the bending effect and thus circular-arc deformation. Besides, a similar phenomenon was reproduced even by changing the element size for the analytical model. Moreover, the circular-arc deformation caused the corner of the stirrup to have an angular opening. Therefore, this movement was also studied by a combination of experiment and analysis to clarify the rupture mechanism.

\section{(3) Behavior of stirrup}

The movement behavior of corner concrete was studied first. Figure $\mathbf{4 1}$ presents a comparison of the angular increment by the stated method in Fig. 23. With respect to the experiment, similar to the time variation in deformation increment (refer to Fig. 35 and Fig. 36), the angle has a significant increase from 
around $4.0 \mathrm{hr}$. After about $11.0 \mathrm{hr}$, due to the convergence of expansion, the angular increment reached a maximum of $1.99^{\circ}$. Caused by the smaller restraint from frame concrete, this value is greater than that of Case 16 of $0.71^{\circ}$ displayed in Fig. 23. Simultaneously, for analysis, the angle of corner concrete holds a similar variation trend to the experiment and the maximum increment value of $1.80^{\circ}$ was obtained, which was similar to the $1.99^{\circ}$ from the experiment.

Correspondingly, the behavior of the inner stirrup was also investigated. Based on the same definition as that adopted in the experiment (Fig. 25). Three points poq with the spacing value of $o p$, oq around 90 $\mathrm{mm}$ were selected in the model of the stirrup (Fig. 42). Therefore, referring to the coordinates for the three points, the detailed spacing values among them were obtained before and after expansion. Further, angle poq is confirmed to have changed from $99.3^{\circ}$ before expansion to $101.8^{\circ}$ after expansion with an angular variation of $2.50^{\circ}$.

Additionally, referring to Fig. 43, which shows the time variation in angular change in Case 14, it is seen that from $8.0 \mathrm{hr}$ to $24.0 \mathrm{hr}$ of expansion, the angular increment for the bent section of the stirrup changes from $1.53^{\circ}$ to $2.50^{\circ}$. A similar variation trend to the movement of corner concrete was verified (refer to Fig. 41). Further, considering the possible correlation, the experimental angular increment in Case 14 is estimated as $2.78^{\circ}\left(1.5 \times 1.85^{\circ}\right)$ from the ratio of circular-arc deformation 1.5 between Case 14 and 16 (refer to Fig. 17 and 18) and the average angular increment $1.85^{\circ}$ in Case 16 . Therefore, for both the analysis and experiment, the same angular increment was confirmed for the bent section of the stirrup.

Summarizing the movements shown in Fig. 44, owing to the effective confinement of the stirrup in a corner area, expansion is relatively small. Whereas, owing to the weak confinement of the stirrup in the central area, maximum expansion resulted. Thus, circular-arc deformation was validated. Additionally, time dependent increase in the angular opening for the corner stirrup was also verified, which further induced the stress concentrations in the stirrup ${ }^{4), 6)}$. In addition, a crack was initiated by the bending process and thus the stress concentration was considered to cause progression of the initial damage until rupture.

\section{CONCLUSION}

To estimate stirrup behavior, which is very influential on a rupture around a stirrup due to ASR, specimens with expansive mortar cast into the frame of ordinary concrete were investigated. Combined with FEM analysis, the mechanism for external damage and its connection with the stirrup motion was studied to confirm the rupture mechanism. The following

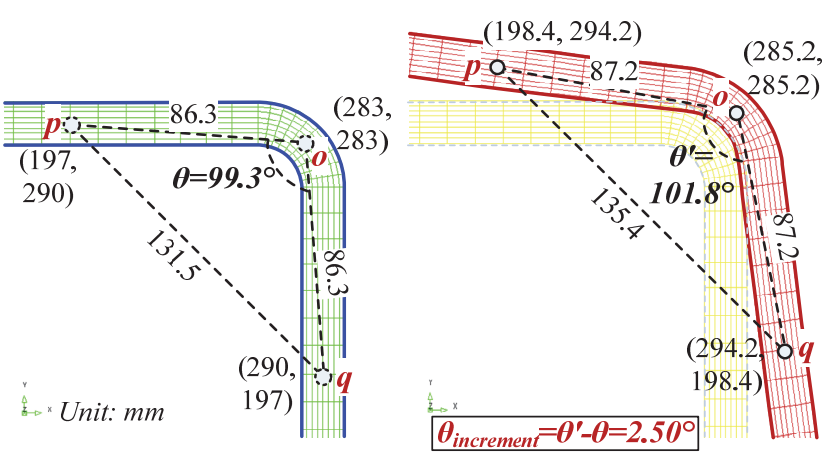

(a) Before expansion

(b) Final state

Fig. 42 Movement of stirrup.

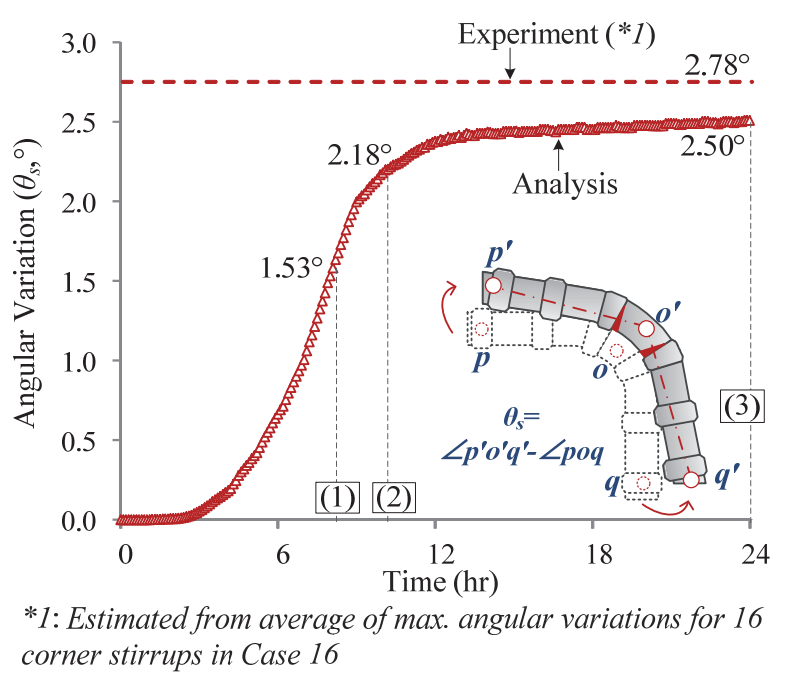

Fig. 43 Angular Variations of Stirrup.

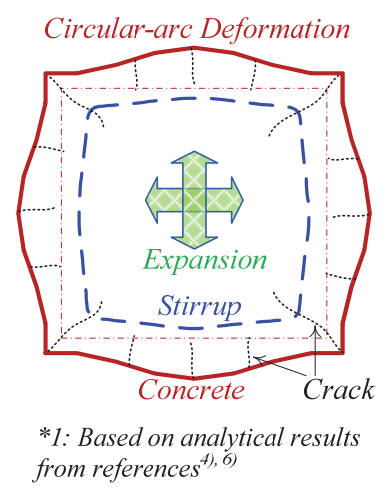

(a). Concrete Movement

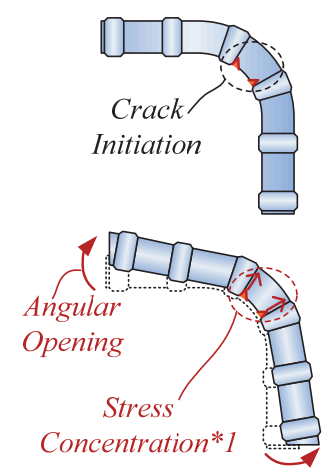

(b). Stirrup Behavior
Fig. 44 Summary of movements.

conclusions were obtained:

(1) Based on the experiment, cracking conditions were evaluated to discuss the effects of ASR-inner expansion. Cracking in external concrete were divided into three types: Type $a$ for cracking generating from the exterior due to the positive bending moment in the center area; Type $b$ for cracking generated from the interior caused by the negative bending effect in 
the corner; and, Type $c$ cracking spreading throughout the diagonal direction by the uniform tension in the corner. With the increase in the size of frame concrete, the amount for each cracking type kept invariant between Cases 14 and 16, which suggests that the cracking form is not influenced by parameters.

(2) Corresponding to cracking, external deformation conditions were evaluated. Deformation was classified as uniform elongation and circular-arc deformation. The experimental results showed that both kinds of deformations generated along with expansion. By increasing the size of the frame concrete, the ratio of circular-arc to uniform elongation raised from 1.5 to 2.6. Greater external restraint causes a greater proportion of circular-arc deformation.

(3) To check the influence on stirrup motion from external deformations, stirrup shapes before and after expansion were recorded. The bent section of the stirrup was verified to have average angular increment of $1.85^{\circ}$. The angular opening of corner stirrup was demonstrated directly. Further, due to the angular opening of corner stirrup, crack initiation in the inner bent section of stirrup was confirmed to progress with the average crack ratio (ratio of crack length to stirrup diameter) increasing from $2.56 \%$ to $17.70 \%$.

(4) To evaluate the mechanism of external damage and stirrup behavior numerically, FEM analysis was conducted. Circular-arc deformation of $4.7 \mathrm{~mm}$ and uniform elongation of $2.6 \mathrm{~mm}$ was validated to be similar to the experimental results of 5.0 and $3.3 \mathrm{~mm}$. Besides, owing to the effective confinement of the stirrup in the corner, expansion was relatively small (average increment of element size of $0.11 \mathrm{~mm}, 2.5$ $\mathrm{mm}$ in total for 22 elements). Whereas, owing to the weak confinement of the stirrup in the central area, maximum expansion resulted (average increment of element size of $0.34 \mathrm{~mm}$, totaling $7.4 \mathrm{~mm}$ for 22 elements).

(5) Based on the analytical results, to check the influence from circular-arc deformation, the stirrup from analysis of Case 14 was also evaluated to have an angular opening of corner stirrup with the maximum angular change as $2.50^{\circ}$, being similar to $2.78^{\circ}$ of the estimated experimental value. Therefore, the angular opening of corner stirrup was validated by both the experimental results and analysis. This was inferred to be very influential on the stress concentration and further the progression of initial damage.

\section{REFERENCES}

1) Torii, K., Yamato, H. and Liu, T.: The feature of steel bar fracturing in ASR-affected bridge pier and its mechanisms, Proceedings of the International Conference on Durability of Concrete Structures, Vol. 1, pp. 453-459, 2008.

2) JSCE: State-of-the-Art Report on the Countermeasures for the Damage Due to Alkali-Silica Reaction, Concrete Library, No. 124, pp. 1-32 1-65, 2005.
3) Sasaki, K., Fujibayashi, M., Tona, M., Sato, A., Hisari, Y. and Miyagawa, T.: Investigation of the cause of reinforcing steel fracture induced by alkali-silica reaction and study on maintenance, Third International Conference on Sustainable Construction Materials and Technologies, 2013.

4) Sasaki, K., Hisari, Y., Igarashi, H. and Miyagawa, T.: Analysis of the strain and stress on bent section of reinforcing bar by finite element method, Proceedings of the Japan Concrete Institute, Vol. 30, No. 1, pp. 987-992, 2008.

5) Kosa, K., Kawashima, Y., Goda, H. and Kouroki, N.: Experimental tests on breaking mechanism of reinforcing bars subjected to alkali silica reaction, Journal of JSCE, Ser. E, Vol. 64, No. 2, pp. 371-388, 2008.

6) Shino, Y., Kosa, K., Matsumoto, S. and Hashiba, M.: Evaluation of damage mechanism for bent part of stirrup, Proceedings of the Japan Concrete Institute, Vol. 26, No. 1, pp. 963-968, 2004.

7) Kosa, K., Kusano, M., Goda, H. and Shibata, A.: Evaluation of deterioration using an ASR-imitated test specimen, Journal of JSCE, Ser. E2, Vol. 69, No. 2, pp. 166-181, 2013.

8) Kusano, M., Kosa, K., Akiyoshi, S. and Goda, H.: Evaluation for progress of stirrup damages using ASR specimens, Proceedings of the Japan Concrete Institute, Vol. 33, No. 1, pp. 989-994, 2011.

9) ACI Committee 223: Expansive cement concretes-present state of knowledge, ACI Journal, Vol. 67, No. 8, 1970.

10) Ueda, N., Sawabe, S., Nakamura, H. and Kunieda, M.: Analytical study on the expansion induced by alkali silica reaction for RC members, Journal of JSCE, Ser. E, Vol. 63, No. 4, pp. 532-548, 2007.

11) Mielich, O., Ozkan, H. and Reinhardt, H. W.: Creep behavior of alkali-silica reaction damaged concrete with slow-reacting aggregates, 15th International Conference on Alkali Aggregate Reaction in Concrete, Sao Paulo, 2016.

12) Giorla, A., Dunant, C., Guidoum, A. and Scrivener, K.: Experimental and numerical study of alkali-silica reaction under multi-axial load, 15th International Conference on Alkali Aggregate Reaction in Concrete, Sao Paulo, 2016.

13) Kobayashi, K., Shiraki, R. and Kawai, K.: Expansion and cracking of concrete structures caused by alkali silica reaction, Seisan Kenkyu, Vol. 40, No. 12, pp. 616-619, 1988. 12.

14) Kagimoto, H., Yasuda, Y., Kinoshita, S. and Kawamura, M.: Mechanisms of ASR surface cracking in a massive concrete cylinder, Concrete Research and Technology, Vol. 25, pp. 201-211, 2014.

15) Hundy, B. B.: Accelerated strain ageing of mild steel, Journal of the Iron Steel Institute, pp. 34-38, 1954.9.

16) Hanshin Expressway Public Corporation: Standard for Maintenance Inspection of Road-structures (Civil Engineering Structure Part), 1985.9.

17) Okamura, H. and Tsuji, Y.: Behavior of chemically prestressed concrete member, Proceedings of JSCE, No. 225, pp. 101-108, 1974.

18) Wu, C., Sato, S., Tezuka, M. and Imai, M.: A study on chemically prestressed concrete slab produced with high expansive concrete, Proceedings of the JCI, Vol. 20, No. 3, pp. 709-714, 1998.

19) Harada, T. and Matsuda, H.: The connecting method of prestressed concrete members by using chemical jack with expansive demolition agent, Proceedings of the Japan Concrete Institute, Vol. 14, No. 1, pp. 177-182, 1992.

20) Kawamura, M. and Iwahori, K.: Expansive pressure caused by alkali silica reaction in mortars under restraint, Concrete Research and Technology, Vol. 14, No. 3, pp. 1-10, 2003.

(Received March 14, 2016) 